\title{
Two degrees and the SDGs: a network analysis of the interlinkages between transnational climate actions and the Sustainable Development Goals
}

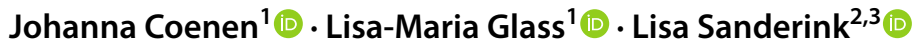

Received: 23 December 2020 / Accepted: 6 July 2021 / Published online: 27 July 2021

(c) The Author(s) 2021

\begin{abstract}
Given the interconnectedness of climate change and sustainable development, policymakers and scholars have started to investigate how climate actions can contribute to achieving the Sustainable Development Goals (SDGs), and vice versa. To date, research has mainly focused on the national and international levels, while little is known about the interlinkages between climate actions and the SDGs at the transnational level. Not only nation states, but also non-state actors undertake ambitious actions designed to reduce greenhouse gas emissions and to promote sustainable development. Using content analysis and network analysis techniques, we examine the interlinkages between the climate actions of 72 transnational initiatives and the 169 targets of the 17 SDGs. We find that actions of 71 initiatives contribute to achieving 16 SDGs, thus generating valuable co-benefits. Besides SDG 13 on climate action and SDG 17 on partnerships for the goals, transnational climate actions frequently address SDGs 9 on industry, innovation and infrastructure, SDG 7 on affordable and clean energy, and SDG 12 on responsible consumption and production. While SDG 3 on good health and well-being and SDG 4 on quality education are barely addressed, SDG 5 on gender equality is not at all covered by transnational climate actions. Additionally, the network reveals that SDG 9 is highly synergistic with many other frequently addressed SDGs and functions as an important connector between them. Finally, our results indicate that transnational initiatives fill a governance gap left by states with regards to SDG 12. Climate initiatives of non-state actors can thus complement state-led actions to implement the Paris Agreement and the SDGs jointly.
\end{abstract}

Keywords Agenda 2030 $\cdot$ SDGs $\cdot$ Paris agreement $\cdot$ Global environmental governance $\cdot$ Network analysis $\cdot$ Synergies

Handled by Fabrice Renaud, University of Glasgow, United Kingdom.

Johanna Coenen

johanna.coenen@leuphana.de

Lisa-Maria Glass

lisa-maria.glass@leuphana.de

Lisa Sanderink

Lisa.Sanderink@vu.nl

1 Leuphana University Lüneburg, Universitätsallee 1, 21335 Lüneburg, Germany

2 Ministry of Economic Affairs and Climate Policy of the Netherlands, Bezuidenhoutseweg 73, 2594 AC The Hague, The Netherlands

3 Vrije Universiteit Amsterdam, De Boelelaan 1111, 1081 HV Amsterdam, The Netherlands

\section{Introduction}

The year 2015 can be considered a landmark year for sustainable development. It saw the adoption of the United Nations' Sustainable Development Goals (SDGs) within the framework of the Agenda 2030 for Sustainable Development, and the Paris Agreement, an international climate agreement under the United Nations Framework Convention on Climate Change (UNFCCC) with the goal of keeping global temperature rise well below two degrees Celsius (United Nations, 2015; UNFCCC 2015). Both climate change and sustainable development involve social, economic, and environmental issues that do not conform to established sectoral and political boundaries. Given strong interlinkages between climate change and sustainable development (Allen et al. 2019; Nerini et al. 2019), leveraging 
synergies in the implementation of these two global agendas can save time and money and enhance efficiency, effectiveness, and coherence (UNFCCC 2017).

Interactions between the SDGs and their targets have gained increased scholarly attention (Bennich et al. 2020; Nerini et al. 2019; Breuer et al. 2019; Le Blanc, 2015; Stafford-Smith et al. 2017; Waage et al. 2015; Weitz et al. 2018). The interrelated nature of the goals poses challenges regarding numerous trade-offs involved, but equally opens a window of opportunity to achieve co-benefits in the implementation when capitalizing on synergies (Scharlemann et al. 2020). The SDGs are seen as a system of interacting components rather than just a collection of goals, targets, and indicators (Pradhan 2019). However, there is little research that has broadened the study of interactions to analyze the synergies arising from a joint implementation of the Paris Agreement and Agenda 2030 based on functional interactions between them. By functional interactions, we are referring to "inherent structural connections between policy domains that are largely independent of the rules and procedures of political institutions in the domain" (van Asselt et al. 2005, p. 257). To date, scholars have mainly examined these interactions at the national level, focusing on the connections between state-led climate actions set out in Nationally Determined Contributions (NDCs) under the UNFCCC and the SDGs (Brandi et al. 2017b; Janetschek et al. 2020; Northrop et al. 2016).

However, not only states, but also non-state actors and collaborative arrangements have gained importance for addressing interrelated global climate change and sustainability problems (Abbott 2012; Biermann and Pattberg 2012; Pattberg and Widerberg 2016). At the national level, research shows that participation of non-state actors in policy-making and implementation is positively correlated with the achievement of many of the SDGs (Glass and Newig 2019). At the global and transnational level, collaborative arrangements in the form of multi-stakeholder partnerships have been described as "the glue for implementation" of the Agenda 2030 (United Nations Development Group 2014, p. 5). These partnerships form an integral part of transnational regime complexes in the area of climate change and sustainable development (Abbott 2012). Such transnational governance arrangements emerged in reaction to the perception that there were increasing regulatory and implementation deficits in multilateral regimes (Bäckstrand 2006) and involve a diverse set of public and private actors (Abbott 2012). Recent empirical evidence suggests that transnational initiatives complement state-led efforts to combat climate change (Andonova et al. 2017; Tosun and Schoenefeld, 2017; Roelfsema et al. 2018). Both inter- and transnational regime complexes have become increasingly fragmented and decentralized (Abbott 2012; Dasandi et al. 2015; Keohane and Victor 2011), giving rise to a situation in which most environmental and sustainability issues are co-governed by multiple institutions involving a diverse set of state and non-state actors. As a result, potential overlaps between these institutions become more likely (Hickmann et al. 2020; Oberthür and Gehring, 2006; Young 2002). An example from our sample of TCIs illustrates this point. The SE4All: Building Efficiency Accelerator aims to "contribute toward the targets for SDG 7 (affordable and clean energy) and achievement of national climate commitments (NDCs)" (Climate Initiatives Platform $2019 \mathrm{~b}$ ), and thus clearly recognizes that the ambitions of transnational climate actions overlap with goals set under the state-led climate agenda and Agenda 2030. In the light of limited human and financial resources, it is particularly important to promote synergies and ensure complementarity between climate actions and sustainable development, thus avoiding inconsistencies, contradictions or duplication of implementation efforts (UNFCCC 2017).

This study follows the underlying assumption that a partial integration of the two post-2015 agendas is feasible and desirable while recognizing, however, that full integration would be neither possible nor preferable. A full integration may undermine the autonomy and focus of the two agendas that have been formulated through distinct processes, involving different actors and legal frameworks (UNFCCC 2017). SDG 13 explicitly states that the "UNFCCC is the primary international, intergovernmental forum for negotiating the global response to climate change" (United Nations 2018, p.14). Since there is little empirical research on the interlinkages between climate change and broader sustainable development at the transnational level, this article explores the extent to which transnational climate initiatives (TCIs) registered at the Non-state Actor Zone for Climate Action (NAZCA) platform ${ }^{1}$ can reinforce and promote sustainable development in accordance with the SDGs. The aim of our research is threefold. First, we examine how the commitments of TCIs contribute towards achieving the SDGs, revealing which SDGs are particularly synergetic with climate actions. Second, we visualize the interlinkages between SDGs and climate actions by applying network analysis techniques. Third, we analyze whether transnational climate actions complement state-led efforts as described in the NDCs. A better knowledge of the thematic overlaps between the Agenda 2030 and climate actions can help both state and non-state actors leverage synergies and co-benefits when designing and implementing transnational climate initiatives.

The remainder of this article proceeds as follows. After introducing the analytical framework, we explain our

\footnotetext{
1 Now referred to as "Global Climate Action portal", but the term NAZCA platform is widely used in academic publications (see e.g. Chan et al. 2019; Hsu et al. 2016; Widerberg, 2017).
} 
methodological approach that combines content and network analysis techniques to identify and visualize interlinkages between climate actions and broader sustainable development. Subsequently, we present our results on the linkages between the commitments of 72 cooperative NAZCA initiatives and the SDGs. We proceed by discussing challenges and opportunities associated with a joint implementation of the post-2015 agendas, focusing on the role of transnational actors. By drawing on findings of previous research, we then compare our results to state-led climate actions laid out in the NDCs. Lastly, we briefly reflect on the strengths and weaknesses of our methodological approach.

\section{Functional interactions and transnational governance}

To analyze the interlinkages between climate change and sustainable development at the transnational level, we focus on two central aspects: First, we build on literature on functional interactions between climate change and sustainable development. Second, we discuss the role of non-state actors in global environmental and sustainability governance in the context of a proliferation of governance arrangements, actors and institutions in recent years.

\section{Functional interactions}

A growing body of literature is concerned with thematic or issue-specific interconnections, also referred to as functional interactions, between the SDGs (Bennich et al. 2020; Le Blanc, 2015; Nilsson et al. 2018; Pradhan et al. 2017; Stafford-Smith et al. 2017; Weitz et al. 2018). Waage et al. (2015) made one of the first contributions to this research area. They group the SDGs into three categories-wellbeing, infrastructure and the natural environment-which emphasize the prospects for synergistic or disruptive interactions. Additionally, Nilsson et al. (2016) developed a framework to map interactions between SDGs, scoring them on a 7-point scale from indivisible to canceling (see also Nilsson et al. 2018). Moreover, researchers have used various approaches to visualize such interactions. For instance, Rockström and Sukhdev (2016) use a "wedding cake" metaphor to map interactions between social, environmental and economic SDGs, while several other studies apply a network perspective to the Agenda 2030 (Le Blanc, 2015; Lusseau and Mancini, 2019; Pham-Truffert et al. 2020; Weitz et al. 2018; Zhou and Moinuddin 2017). In short, these efforts commonly pursue a systematic understanding of functional interactions to support an integrated approach towards the SDGs.

Functional interactions are not only visible among the SDGs alone, but also in relation to the climate targets under the Paris Agreement. Most obviously, SDG 13 on climate action is highly relevant to the Paris Agreement. From a broader perspective, climate change is interlinked in both cause and effect with most areas of human and sustainable development. For instance, progress towards SDGs related to energy, cities and infrastructure is likely to address some of the fundamental causes of climate change; and activities on SDGs related to hunger, water or health will presumably increase resilience to climate change (UNFCCC 2017). Conversely, implementation of climate policy can strongly affect SDG achievement (von Stechow et al. 2016). For example, a rising demand for bioenergy could have a negative effect on food and water security, which relate to SDG 2 and 6, respectively. A growing body of literature is concerned with such functional interactions between climate actions and development policies (Eriksen et al. 2011; Smit and Pilifosova 2001; van Asselt et al. 2005). Scholars have explored how to connect the fields of climate change and sustainable development by reducing trade-offs and supporting synergies that may result from these interactions (Beg et al. 2002; Mayrhofer and Gupta 2016; von Stechow et al. 2015, 2016; Weitz et al. 2018). In 2016, the World Resource Institute published an interactive tool that identifies potential alignments between the SDGs and the targets, actions and policy measures set out in the NDCs (Northrop et al. 2016). One year later, the German Development Institute and the Stockholm Environmental Institute analyzed and compared how climate actions formulated in the NDCs correspond to each of the 17 SDGs (Brandi et al. 2017b). Similarly, Janetschek et al. (2020) explored connections between the Paris Agreement and the Agenda 2030 across all NDCs and more detailed interactions at SDG target level for a subset of six developing countries. At the national and regional level, researchers have analyzed the alignment between the NDCs and SDGs for West Africa (Antwi-Agyei et al. 2018), South Africa (England et al. 2018) and Mexico (GIZ 2018).

\section{Transnational governance}

The proliferation of actors, governance arrangements and institutions in global governance has been discussed primarily within three major strands of research. By referring to the concepts of fragmentation (Biermann et al. 2009), polycentricity (Jordan et al. 2018), and complexity (Orsini et al. 2019), scholars have described the emerging ever more diverse global governance architecture and the potentially complementary or conflictive interactions between actors and institutions from separate but partially overlapping perspectives. While causes, consequences and policy implications differ depending on the analytical concept applied, it is important to note that they are not mutually exclusive 
and their structural features are often found simultaneously (Kim 2020).

The areas of climate change and sustainable development have certainly seen a proliferation of governance arrangements in recent years. For instance, there are over 3,000 multilateral and bilateral environmental agreements to date (Mitchell et al. 2020). Yet, climate commitments by nation states under the Paris Agreement to limit global warming to $1.5 / 2{ }^{\circ} \mathrm{C}$ remain insufficient (Rogelj et al. 2016), and deficits with regard to other areas of sustainable development also persist (Chan et al. 2019). While this by no means implies that state actors have become superfluous in global environmental and sustainability governance, these gaps underline the importance of non-state and transnational action in complementing state-led efforts (Andonova et al. 2017; Chan and Amling, 2019; Hickmann, 2017). With non-state actors we refer to economic actors, subnational actors (such as cities and municipalities), as well as social movements and civil society (Bäckstrand et al. 2017). These fulfill a variety of governance functions, including defining problems, stimulating dialog, sharing knowledge and information, building capacity, shaping rules and norms, transferring technology, providing finance, pooling resources and mobilizing public engagement (Bäckstrand et al. 2017; Chan et al. 2019). We speak of transnational governance "when non-state and/or sub-state actors in at least two different states adhere to rules and practices that seek to steer behavior toward shared, public goals" (Andonova et al. 2017, p. 254). Although various scholars criticize the added value, effectiveness and legitimacy of transnational and non-state initiatives (Bäckstrand et al. 2017; Bulkeley et al. 2012; Hickmann 2017; Kuyper et al. 2018), a growing body of literature stresses how transnational and non-state action bridge governance gaps, for example related to implementation and participation (Börzel and Risse 2010; Chan et al. 2019; Roelfsema et al. 2018; Tosun and Schoenefel 2017).

In short, scholars have made detailed efforts to study interactions among the SDGs, and between the SDGs and the global climate targets, particularly in the international realm. However, given a proliferation of actors and institutions in global environmental and sustainability governance, it is important to further expand the body of empirical research on these interactions with a specific focus on the transnational level. Since intergovernmental and transnational spheres of global climate and sustainability governance can mutually reinforce each other (Andonova et al. 2017; Bäckstrand, 2006; Chan et al. 2016), it is important to determine the extent to which interlinkages between the two agendas at the intergovernmental level compare to those at the transnational level.

\section{Methods and materials}

Our analysis of the interlinkages between TCIs and the SDGs is based on a detailed content and network analysis of 72 multi-actor climate initiatives. We coded interlinkages when TCIs make reference to the content of a specific SDG target, indicating that the proposed climate action will contribute to progress towards the SDGs (i.e., synergies between climate action and SDGs). We undertook this analysis in three steps. First, we retrieved complementary information about, for example, each initiative's goals, activities and participants from the NAZCA platform ${ }^{2}$ and the Climate Initiatives Platform ${ }^{3}$ (CIP). We drew on both databases because they provide more data for the subsequent content analysis than a single source alone. At the time of data collection (May 2018), 77 cooperative initiatives were registered on the NAZCA platform, but comprehensive information was available for only 72 of these initiatives on the CIP platform. Thus, we restricted our sample size to 72 , thereby ensuring a high level of data consistency and comparability. We created a text document for every initiative, synthesizing the available information from both data platforms. Cooperative initiatives registered at the NAZCA platform are typically multi-actor and in many cases multi-sectoral partnerships aimed at addressing climate change. They involve several participants from different countries, and at least one nonstate actor (i.e., company, city, organization or investor). For instance, the CEM: Global Lighting Challenge involves 2 regions, 11 companies and 16 countries (Climate Initiatives Platform 2019a).

Second, we conducted a qualitative content analysis to systematically examine the textual information of the 72 TCIs for references to the 17 SDGs and their 169 targets. We coded text segments that reflect the content of the SDGs (see Appendix A2 for examples; methodological approach inspired by Brandi et al. (2017a, b)). When an initiative addressed at least one specific target, we linked it to the respective SDG. Since coding is an interpretive process, two authors first conducted the content analysis independently. To reach intercoder agreement, both coders discussed and resolved inconsistencies between their individual coding results. In particularly difficult cases, all three authors discussed inconsistencies so as to ensure a high reliability of the results. Some discussions revolved around the vague wording of the SDGs, which include broad phrases like "modern energy services" (target 7.1), "inclusive and

\footnotetext{
${ }^{2}$ Non-state Actor Zone for Climate Action (NAZCA) / Global Climate Action portal. https://climateaction.unfccc.int/. Last accessed on June 22, 2020.

${ }^{3}$ Climate Initiatives Platform. http://climateinitiativesplatform.org. Last accessed on June 22, 2020.
} 
sustainable urbanization" (target 11.3) and "awareness raising" (target 13.3), which leave much room for interpretation. We excluded targets 17.16 and 17.17 (strengthening and promoting multi-stakeholder partnerships) from the analysis, as they apply to the entire dataset. We note that there are several targets that non-state actors cannot address as they fall primarily under the purview of governmental actors (e.g., target $1.3^{4}$ and target $5 . c^{5}$ ). While we acknowledge that non-state actors might be able to influence domestic policymaking, we decided to adhere to the specific wording of the targets. Thus, according to our methodological approach, there cannot be a $100 \%$ alignment between transnational climate initiatives and some SDGs on a target level.

The third step of the analysis involved data visualization through the use of bar charts and networks. First, we visualized the quantitative links between TCIs and the SDGs in descriptive graphs. While it is possible to discern some patterns (e.g., the relative frequency of particular SDGs addressed by climate initiatives) directly from the charts, a systematic study of the interlinkages between TCIs and the SDGs called for a more sophisticated methodology. To this end, we analyzed the data further using network techniques. Up until now, network analysis in social science research has been used mainly for studying relationships among societal entities, such as people, groups, or organizations (e.g., Widerberg 2017), or to analyze citation networks (e.g., Kim 2013). In recent years, a small but growing body of research has applied a network perspective to examine SDG interlinkages (GIZ 2018; Le Blanc 2015; Putra et al. 2020; Weitz et al. 2014, 2018; Zhou and Moinuddin 2017). A network is a structure consisting of a set of nodes (objects) and set of edges (ties). Our network analysis employs two sets of nodes (climate initiatives and SDGs on both a goal and target level) which are linked through edges where the coding analysis revealed a thematic overlap between a climate initiative and the SDG or target. We present our data in a two-mode network (including both sets of nodes) and one-mode networks (including only one set of nodes). ${ }^{6}$ To identify SDGs that are particularly important in the network, we analyze degree centrality, betweenness centrality and eigenvector centrality. According to Zhou and Moinuddin (2017), who interpret these network measures in the context of SDG networks, SDGs with high degree centrality connect with many other SDGs. SDGs with high betweenness centrality act as important intermediates bridging unconnected SDGs. Lastly,

\footnotetext{
${ }^{4}$ SDG target 1.3: "Implement nationally appropriate social protection systems [...]"(United Nations 2018, p. 1).

5 SDG target 5.c: "Adopt and strengthen sound policies and enforceable legislation for the promotion of gender equality [...]" (United Nations 2018, p. 7)

${ }^{6}$ We used the qualitative coding softwares ATLAS.ti and MAXQDA for the content analysis, and Gephi for the network analysis.
}

SDGs with high eigenvector centrality interact with many other SDGs and place at strategic positions in connecting with other influential SDGs.

Network analysis techniques are a useful tool to represent the web of connections between various units. The networks illustrate the underlying structure of the interlinkages and elucidate the relative importance of individual nodes based on their position in the network (Hanneman and Riddle 2005). These techniques provide significant added value to our data set by revealing the position of individual SDGs within the whole system and by visualizing which SDGs are closely interlinked through transnational climate actions. Networks provide a comprehensive overview of a large quantity of connections and make information easily accessible and understandable. They demonstrate which goals and targets can be grouped together due to their thematic interactions and interdependencies and reveal that many targets are inherently cross-sectoral.

\section{Results}

Our analysis proceeds in two steps. We first examine to what extent climate initiatives propose actions that link to the SDGs (i.e., SDG coverage) before subsequently investigating the interlinkages between TCIs and the SDGs using network analysis techniques.

\section{Analysis of SDG coverage}

We found that nearly all transnational climate initiatives involve climate actions that contribute to achieving the SDGs. Out of 72 initiatives, 71 demonstrate connections to the SDGs in their proposed actions. Only the Montreal Carbon Pledge initiative, which aims to "measure and publicly disclose the carbon footprint of their [investors'] investment portfolios on an annual basis" (NAZCA, n.d.-a) does not include any linkages to the SDGs. Although target 10.5 addresses the broader financial system ("Improve the regulation and monitoring of global financial markets and institutions"), there is no specific target focusing on financial investors or sustainable investment portfolios specifically.

As expected, most TCIs (35 out of 72; 49\%) demonstrate a link to SDG 13 on climate action (Fig. 1). Additionally, we found that the non-state actor climate initiatives analyzed contribute to 15 other SDGs. Thirty-four initiatives (47\%) reference the content of SDG 12 (responsible consumption and production), followed by 33 initiatives (46\%) that link to SDG 9 on industry, innovation and infrastructure. Thirty-one initiatives (43\%) promote access to energy, energy efficiency or the use of renewable energy as set out in SDG 7. SDG 17 on partnerships for the goals is addressed by 27 initiatives (38\%), while 20 initiatives (28\%) contribute to SDG 11 on 


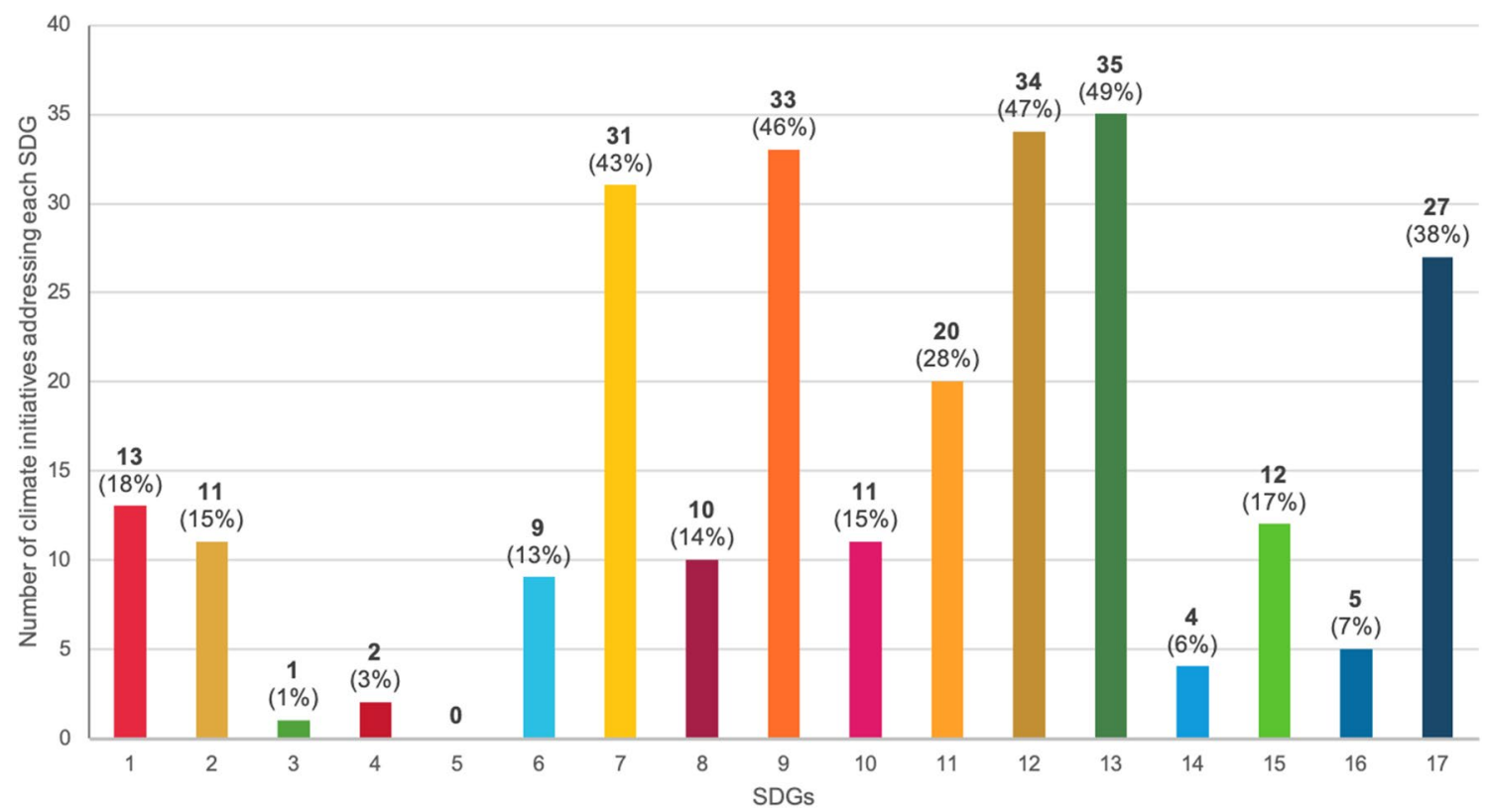

Fig. 1 Interlinkages between 72 transnational climate initiatives and the SDGs at the goal-level. Each initiative may relate to several SDGs
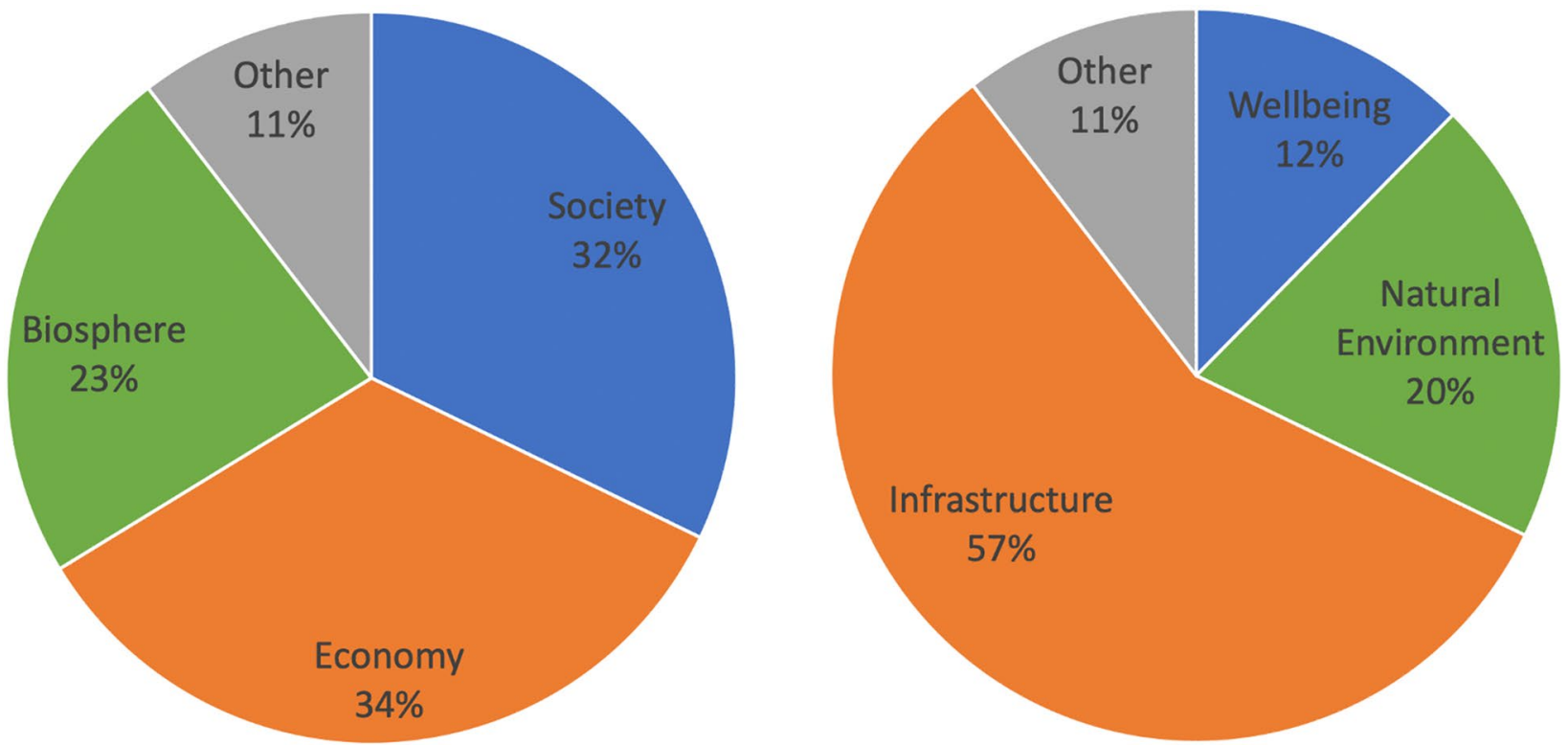

Fig. 2 Coverage of SDGs by transnational climate actions, grouped according to the categorizations proposed by Rockström and Sukhdev (2016) on the left and Waage et al. (2015) on the right

sustainable cities. The initiatives cover SDG 14 (life below water, 6\%) and SDG 16 (peace, justice and strong institutions, 7\%) only marginally. While SDG 3 (good health and well-being) and SDG 4 (quality education) are addressed by only one and two initiatives, respectively, no initiative explicitly refers to SDG 5 on gender equality. We note that some TCIs refer to the importance of the inclusion of women in general. For reasons of consistency, however, we did not code these text sections because the initiatives made no reference to a specific target under SDG $5 .^{7}$

\footnotetext{
7 For example, the "Save Food Initiative" aims to ensure "food security and nutrition for the world's poorest and most vulnerable communities, particularly women [...] (Climate Initiatives Platform 2018a, b), yet this does not relate to any specific target under SDG 5.
} 


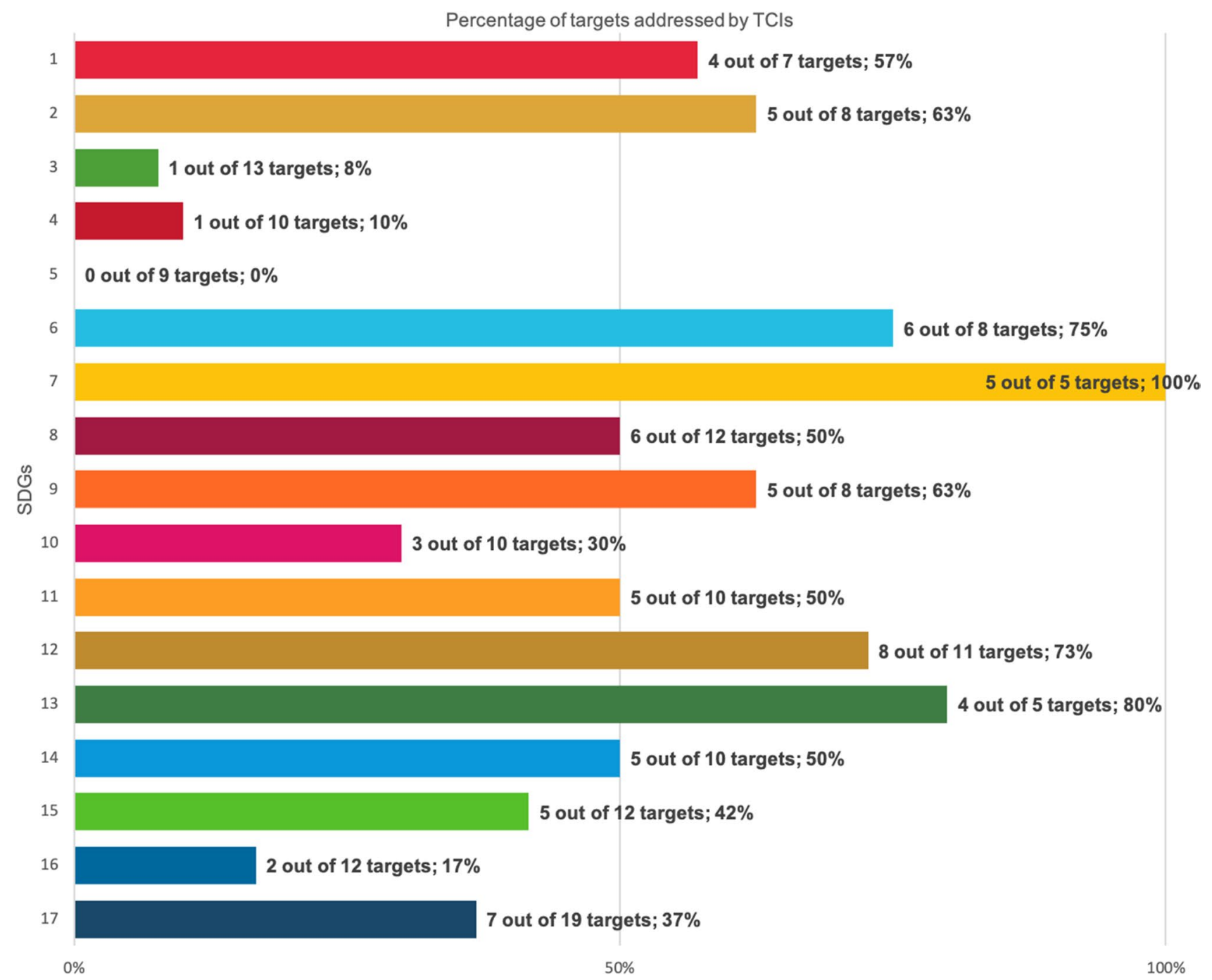

Fig. 3 Interlinkages between 72 transnational climate initiatives and the SDGs at the target level

Furthermore, we analyzed the SDG coverage according to the categorizations proposed in previous research (Fig. 2). Following Rockström and Sukhdev's approach (2016), we found that the initiatives address economic SDGs the most (34\%). The coverage for social SDGs is almost equally high, with $32 \%$ of initiatives addressing that dimension. Only $23 \%$ of all covered SDGs relate to the natural environment. However, a very different picture emerges when applying the categories developed by Waage et al. (2015). While initiatives cover SDGs related to infrastructure (SDGs 2, 6, 7, 8, 9, 11 and 12) most often (57\%), only $20 \%$ of initiatives address SDGs on the natural environment (SDGs 13, 14 and 15). Notably, initiatives cover SDGs on wellbeing (SDGs 1, 3, 4, 5, 10 and 16) the least (12\%). Grouping the SDGs into different categories underlines that socio-economic SDGs feature more prominently than environmental SDGs in transnational climate actions. Infrastructure appears to be a crosscutting theme, connecting many transnational climate actions.

As Fig. 3 shows, the TCIs analyzed in this study can be linked to 71 out of 169 total targets under the SDGs. SDG 7 (affordable and clean energy) is the only goal for which TCIs address all of its targets. Further, we found interlinkages with the majority of targets for SDGs 1 (no poverty), 2 (zero hunger), 6 (clean water and sanitation), 9 (industry, innovation and infrastructure), 12 (responsible consumption and production) and 13 (climate action). For SDGs 8 (decent work and economic growth), 11 (sustainable cities and communities) and 14 (life below water), the results show linkages with $50 \%$ of the targets. Notably, the data show a particularly low degree of interlinkages between TCIs and the targets of SDGs 3 (good health and well-being), 4 (quality education) and 16 (peace, justice and strong institutions). In absolute terms, we found that TCIs address target 12.6 


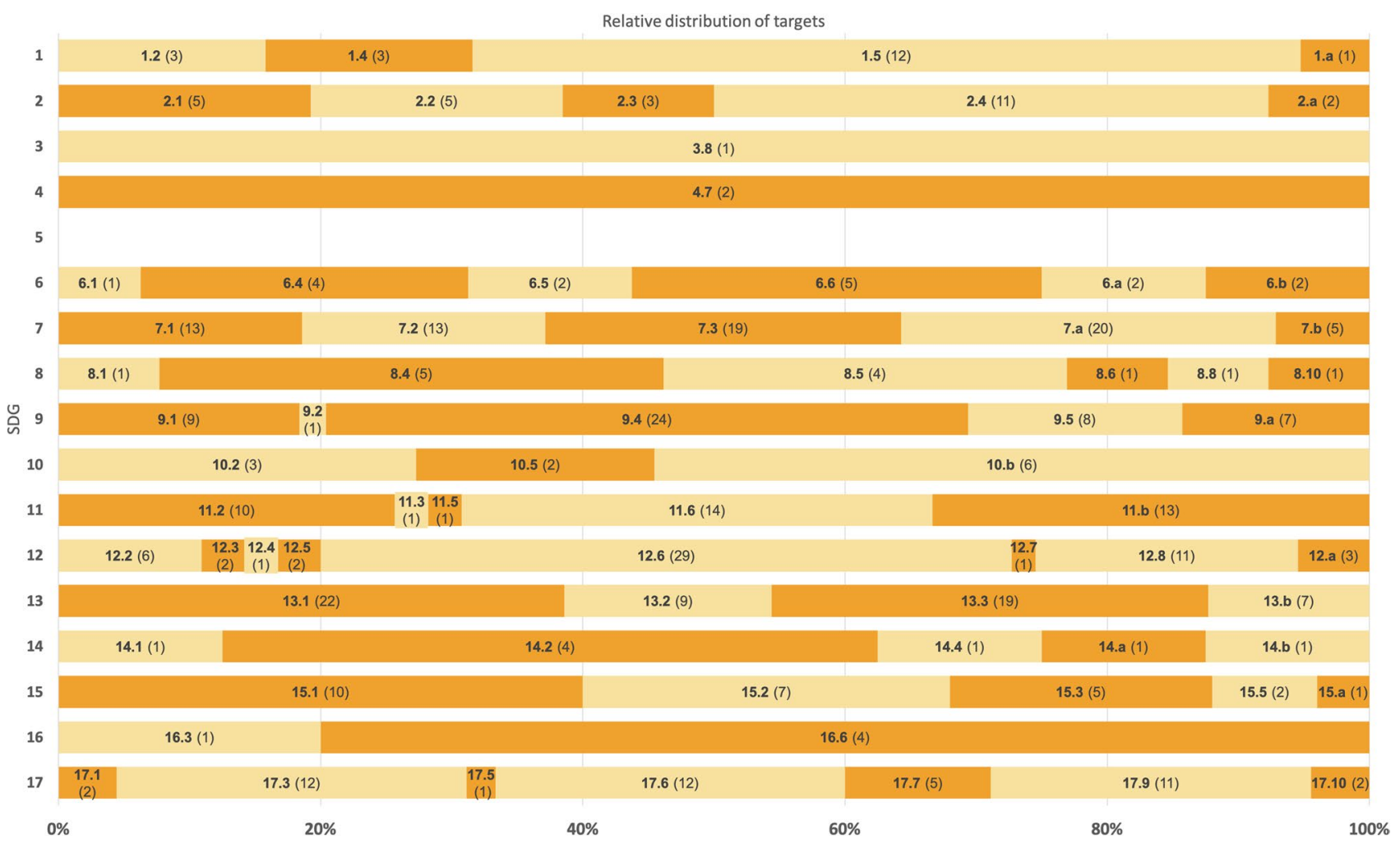

Fig. 4 Relative distribution of targets across the SDGs. This figure shows the extent to which TCIs address individual targets under each goal. The bold numbers in the bars indicate the SDG targets and the numbers in brackets denote the absolute number of linkages between TCIs and targets

It is striking that SDG target 12.6 (sustainable business practices) covers slightly over half of the interlinkages pertaining to SDG 12. Given that SDG 12 is the second-most frequently addressed SDG, this finding indicates that TCIs are strongly focused on fostering sustainable practices in the private sector. Regarding SDG 9 (industry, innovation and infrastructure), target 9.4 (sustainable infrastructure and retrofitted industries) is prominent, accounting for $49 \%$ of targets addressed under this goal. With regards to SDG 7 (affordable and clean energy), which also shows great potential to create synergies between the climate and the Agenda 2030 (i.e., 43\% coverage on a goal level), the targets that TCIs addressed were generally spread evenly. Our results demonstrate that TCIs covered target 7.a (access to clean energy research and technology) the most in relative terms with $29 \%$, followed by target 7.3 (energy efficiency) with $28 \%$. Targets 7.1 (access to energy services) and 7.2 (renewable energy) both make up 19\%. This indicates that TCIs often focus on research and technology transfer in the field of energy. Under SDG 16 on peace, justice and strong institutions, only targets 16.6 (effective institutions; addressed by four initiatives) and 16.3 (rule of law; addressed by one initiative) show interlinkages with TCIs. For both SDG 3 (good health and well-being) and SDG 4 (quality education), 
we found that the analyzed initiatives link to only one target each, being target 3.8 (universal health coverage; addressed by one initiative) and target 4.7 (provide learners with knowledge and skills to promote sustainable development; addressed by two initiatives), respectively.

\section{Network analysis}

To advance our analysis and visualize the results, we used network analysis techniques to examine the data. An interactive version of this network can be accessed online. ${ }^{8}$ Figure 5 outlines the overall structure of the network, comprising two sets of nodes (SDGs at the goal and target level and TCIs). ${ }^{9}$ The edges represent thematic interlinkages between TCIs and the SDGs. The network includes 158 nodes ( 16 goals, 71 targets and 71 initiatives) out of 258 possible nodes (17 goals, 169 targets and 72 initiatives). Isolates, which are nodes that are not connected to other nodes, have been filtered out. On average, every node is connected to 8.9 other nodes (see supplementary material A1a). However, there is a high variance in the number of connections that the nodes have, which is represented by the size of the nodes in Fig. 5 . In the network, linked nodes are attracted to each other and non-linked nodes are pushed apart, thereby emphasizing complementarities.

SDG 17 (partnerships for the goals) is located at the center of the network. This indicates that this goal is highly synergistic; TCIs address SDG 17 in combination with a wide range of other SDGs. The network analysis thus corroborates the claim by several scholars that SDG 17 is a cross-cutting goal that supports the implementation of all other goals (Le Blanc 2015; Waage et al. 2015). As expected, SDG 13 on climate action is located near SDG 17 in the central area of the network. It shows the highest degree centrality within the network (35), connecting to 35 initiatives. The results also show high degree centrality for SDGs 12 (responsible consumption and production; 34), 9 (industry, innovation and infrastructure; 33) and 7 (affordable and clean energy; 31 ), highlighting priority areas of the TCIs.

Looking at the position of the initiatives in the network helps to identify functional interactions between the SDGs through the climate actions of TCIs. For example, initiatives that are grouped between SDGs 12 (responsible consumption and production), 9 (industry, innovation and infrastructure) and 7 (affordable and clean energy) mainly concern climate actions in the private sector; they typically have

\footnotetext{
${ }^{8}$ See https://kumu.io/-/202345\#map-UsyuvvlU

9 We apply different colors to the SDGs and targets to increase the readability of the figure even though they belong to the same set of nodes in this two-mode network.
}

a particular focus on retrofitting industries and promoting cleaner, more efficient energy use. For example, the initiative United for Efficiency (I_69) aims to support "emerging economies to switch their markets to energy-efficient products" (Climate Initiatives Platform 2019c) by engaging with manufacturers of appliances and equipment, such as refrigerators, lighting and air conditioners. Additionally, initiatives located between SDG 7 (affordable and clean energy), 9 (industry, innovation and infrastructure) and 11 (sustainable cities and communities) often relate to climate actions in urban areas, particularly energy efficiency in urban transportation. At the upper part of the network, many initiatives are centered between SDG 2 (zero hunger), 6 (clean water and sanitation), 1 (no poverty) and 14 (life below water). Most of these initiatives are concerned with resilience-building and sustainable practices in the aqua- and agricultural sectors, focusing on smallholders and the most vulnerable parts of the population. Interestingly, however, while the network reveals strong functional interlinkages between the SDGs that address water- and food-related topics, it does not support the often-cited water-energy-food nexus, with SDG 7 (affordable and clean energy) placed at the other end of the network. This tends to corroborate the argument of some scholars that governance arrangements across these three potentially highly synergetic sectors still remain fragmented (Weitz et al. 2017).

Scholars rarely analyze multi-mode networks (Fig. 5) without transforming them into one-mode networks, which include only one type of nodes. This process, called projection, is important for a more in-depth analysis because most network measures are solely defined for one-mode networks (Opsahl, 2013). Figures 6 and 7 depict projected networks. In both of these projected networks, SDGs or targets that are addressed by the same initiative(s) are shown as being linked. SDGs which are connected through a strong edge are arguably synergistic because they are often addressed jointly. In Fig. 6, the strongest connection exists between SDG 9 (industry, innovation and infrastructure) and SDG 7 (affordable and clean energy), with 21 climate initiatives proposing actions related to both themes. A sub-group of SDGs that appears in the shape of a pentagon (i.e., SDG 7, 9, 11, 12, 13 and 17) is particularly well connected. SDG 9 (industry, innovation and infrastructure) is at the center of the pentagon, indicating that many frequently addressed SDGs are synergistic with this goal. These projected networks suggest that infrastructure is a cross-cutting theme that ties the SDGs closer together; SDG 9 relates to many other goals, such as SDGs 7 (e.g., energy infrastructure), 11 (e.g., urban infrastructure) and 12 (e.g., waste infrastructure). This corroborates findings of previous research suggesting that infrastructure-related goals and targets show great synergistic potential to achieve the SDGs (Adshead et al. 2019; Waage et al. 2015). Additionally, SDGs 7, 8, 9 and 17 have 


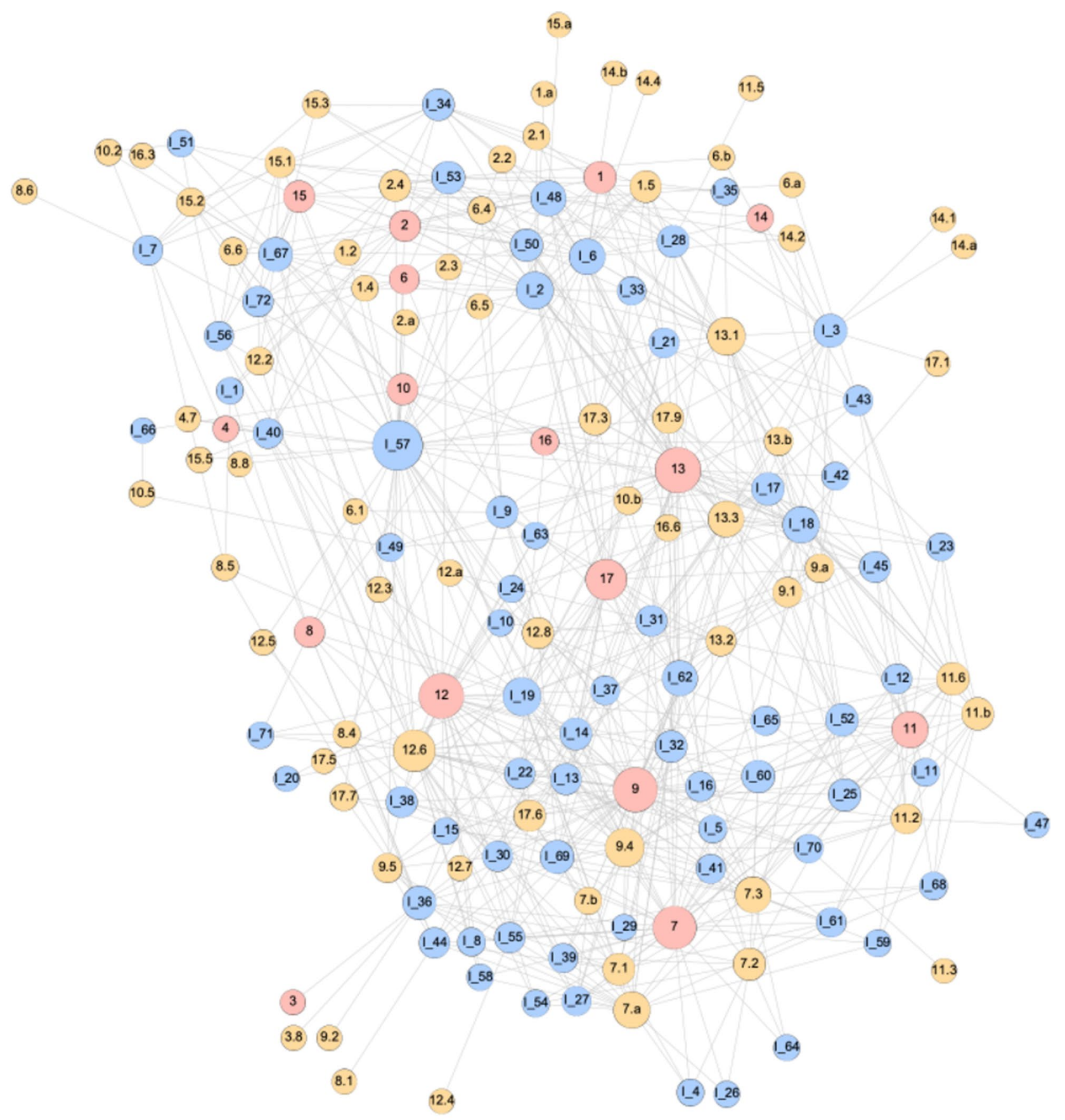

SDG Abbreviation

1. No poverty

2. Zero hunger

3. Good health and well-being

4. Quality education

5. Gender equality

6. Clean water and sanitation
7. Affordable and clean energy

8. Decent work and economic growth

9. Industry, innovation and infrastructure

10. Reduced inequalities

11. Sustainable cities and communities

12. Responsible consumption and production
13. Climate action

14. Life below water

15. Life on land

16. Peace, justice and strong institutions

17. Partnerships for the goals the highest betweenness centrality and eigenvector centrality in the network (supplementary material S1b). This underlines that these SDGs function as connectors between pairs of otherwise unconnected SDGs, while also being connected to many other important SDGs in the network. Furthermore, these findings demonstrate the analytical value of the 
४Fig. 5 Overall structure of the network: SDGs (red), targets (orange) and initiatives (blue). We applied a force-based layout, which means that linked nodes are attracted to each other and non-linked nodes are pushed apart, thereby emphasizing complementarities. This network consists of two sets of entities (SDGs on both a goal and target level, and initiatives). Edges only exist between nodes belonging to different sets. The size of the node indicates degree centrality: the more connections a node has with other nodes, the bigger it appears. Isolates have been filtered out (degree range $\geq 1$ ). See Appendix A1 for the full names of the initiatives. Interested readers can explore our network interactively at: https://kumu.io/-/202345\#map-UsyuvvlU

network analysis. Arranging the SDGs in a network structure reveals synergies between the goals and the importance of individual SDGs that function as connectors.

By examining the network data at a target level (Fig. 7), an even more nuanced picture emerges. Target 12.6 (sustainable business practices) bridges different subgroups of the network. Furthermore, target 9.4 (sustainable infrastructures and retrofitted industries) is synergistic with many other targets, particularly targets 12.6 (sustainable business practices) ${ }^{10} 7.3$ (energy efficiency) ${ }^{11}$ and 7.a (access to clean energy research and technology). ${ }^{12}$ For example, the proximity between targets 7.3 and 9.4 illustrates the strong thematic overlap between both targets. Initiatives that aim to upgrade infrastructure and retrofit industries are likely to address energy efficiency issues. Target 13.1 (climate change adaptation) has the highest degree centrality, meaning that it links to the highest number of other targets. The network also underlines the synergistic potential of certain pairs of SDGs, which have strong connecting ties. For instance, climate initiatives often address target 13.1 (climate change adaptation) in conjunction with target 1.5 (resilience of the poor); both targets relate to resilience-building. Lastly, Fig. 7 underlines the importance of target 17.3 (mobilize additional financial resources), which is located at the center of the network and has the second highest high eigenvector centrality in this network after target 17.9 (capacity building in developing countries). Previous research has shown that the provision of financial resources is a cross-cutting theme, which serves as a crucial enabling factor for SDG achievement at the national level (Glass and Newig, 2019). Our results tend to corroborate this finding in the realm of transnational climate actions.

\footnotetext{
${ }^{10}$ Fourteen initiatives address both targets in their actions.

11 Twelve initiatives address both targets in their actions.

12 Nine initiatives address both targets in their actions.
}

\section{Discussion}

Our results demonstrate that activities set out in TCIs have a high potential to contribute to the achievement of the SDGs. Functional interactions between climate actions and the SDGs are particularly prominent in the areas of energy (SDG 7), infrastructure (SDG 9) and consumption and production (SDG 12). Since the TCIs we analyzed usually relate to several SDGs in their proposed actions, it is clear that TCIs can generate several co-benefits simultaneously. Our discussion of the results proceeds in three steps. First, we discuss the role of transnational actors in the joint implementation of the two post-2015 agendas and detail associated challenges and opportunities. Second, we relate our findings to previous research by illustrating how climate initiatives by non-state actors address both agendas jointly in comparison to state-led actions (i.e., NDC-SDG linkages). Third, we briefly reflect on the strengths and weaknesses of our methodological approach.

First, our results illustrate that non-state actors can perform climate actions that contribute to meeting the objectives of both post-2015 agendas. While the primary focus of state actors arguably lies at the implementation of the agendas at the national level, transnational multi-stakeholder initiatives can facilitate the exchange of information and experiences across national borders. Since transnational initiatives can target specific stakeholder groups (e.g., Adaptation for Smallholder Agriculture Programme ${ }^{13}$ ), specific sectors (e.g., Life Beef Carbon Initiative ${ }^{14}$ ), specific problem areas (e.g., remove commodity-driven deforestation ${ }^{15}$ ) and specific regions (e.g., Clean Energy Corridors in Africa ${ }^{16}$ ), they can transfer financial, human, knowledge and material resources to participants and beneficiaries who are located in geographically distant places. Thus, TCIs can bring together actors from various organizations and locations who work on similar issues. In doing so, TCIs facilitate mutually beneficial relationships by pooling different actors' capacities and expertise regarding the achievement of a low-carbon and climate-resilient development. Transnational governance arrangements are constantly increasing, which is well illustrated by the fact that the number of cooperative initiatives registered at the NAZCA platform almost doubled since we retrieved our data in 2018. This demonstrates that responses

\footnotetext{
$\overline{13}$ See https://climateaction.unfccc.int/views/cooperative-initiativedetails.html?id=4

${ }^{14} \mathrm{See}$ https://climateaction.unfccc.int/views/cooperative-initiativedetails.html?id=41

15 See https://climateaction.unfccc.int/views/cooperative-initiativedetails.html?id=71

${ }^{16}$ See https://climateaction.unfccc.int/views/cooperative-initiativedetails.html?id=19
} 


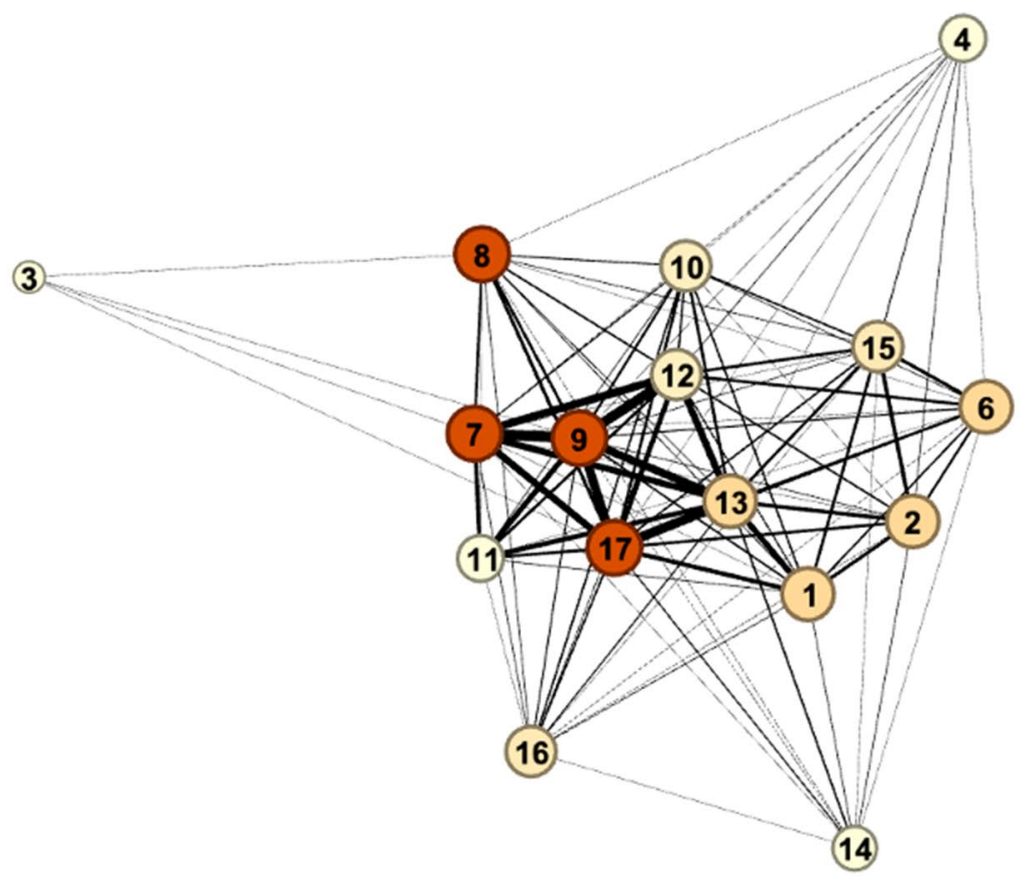

\section{SDG Abbreviation}

1. No poverty

2. Zero hunger

3. Good health and well-being

4. Quality education

5. Gender equality

6. Clean water and sanitation
7. Affordable and clean energy

8. Decent work and economic growth

9. Industry, innovation and infrastructure

10. Reduced inequalities

11. Sustainable cities and communities

12. Responsible consumption and production
13. Climate action

14. Life below water

15. Life on land

16. Peace, justice and strong institutions

17. Partnerships for the goals
Fig. 6 Links between the SDGs through TCIs. We applied a forcebased layout. The color of the nodes indicates betweenness centrality: the darker the node, the more often this node lies on the shortest path between two other nodes. Nodes with a high betweenness centrality

to pressing societal challenges like climate change are not limited to public policy and state-led actions, but increasingly include activities by a multitude of public, private and civil society actors.

However, the phrasing of several SDGs and targets suggests that actions concerning certain development goals only concern the state and do not apply to non-state or subnational actors. The only explicit reference to businesses, for example, can be found in target 12.6, which encourages companies to adopt sustainable practices. Hajer et al. (2015, p. 1652) criticize the SDGs for following a logic of "cockpitism", which refers to the perception that top-down steering by governments and intergovernmental organizations can solve global problems. While references to domestic policymaking and implementation in the SDGs do not exclude the possibility of involving other stakeholders, at present, the responsibilities, capabilities and interests of subnational and non-state actors find only limited recognition in the Agenda 2030. Mainstreaming the contribution of non-state actors into specific targets could lead to an increased sense of connect pairs of other nodes that would otherwise not be able to reach one another. The thicker the edge between two nodes, the more often initiatives address this pair of SDGs jointly. The network metrics can be found in supplementary material (S1)

responsibility and accountability among various stakeholders. For example, targets dealing with the means of implementation (e.g., target 1.a, 1.b) could differentiate between stakeholder groups so as to convey a strong sense of ownership, responsibility and accountability. At the national level, governments could encourage inclusivity, accountability and transparency in SDG implementation efforts by establishing a recurrent review process involving all stakeholders.

Our results indicate that some SDGs show greater potential for alignment with climate actions than others based on their stronger functional linkages with climate change. While some SDGs have inherent connections with the climate agenda, such as target 7.2 (renewable energy), other SDGs require deliberate decisions and actions if they are to be mainstreamed in climate initiatives, such as target 4.7 (ensure that all learners acquire the knowledge and skills needed to promote sustainable development). However, we do not argue that TCIs should address all SDGs equally, or that some SDGs should be prioritized. It might be worth exploring why TCIs address some SDGs only marginally, 


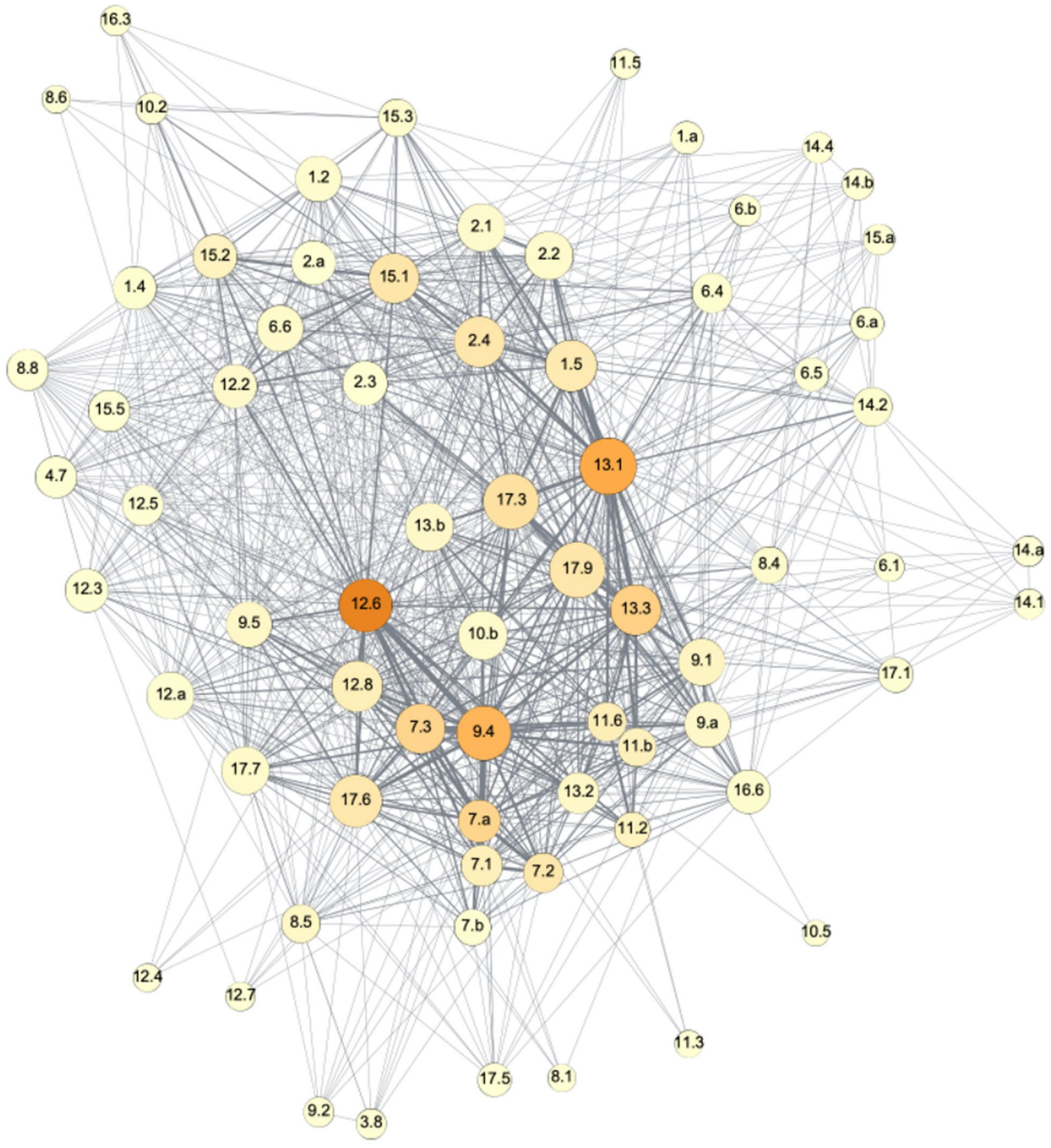

\section{SDG Abbreviation}

1. No poverty

2. Zero hunger

3. Good health and well-being

4. Quality education

5. Gender equality

6. Clean water and sanitation
7. Affordable and clean energy

8. Decent work and economic growth

9. Industry, innovation and infrastructure

10. Reduced inequalities

11. Sustainable cities and communities

12. Responsible consumption and production
13. Climate action

14. Life below water

15. Life on land

16. Peace, justice and strong institutions

17. Partnerships for the goals
Fig. 7 Links between the SDG targets through initiatives. We applied a force-based layout. The color of the nodes indicates betweenness centrality: the darker the node, the more often this node lies on the shortest path between two other nodes. Nodes with a high betweenness centrality connect pairs of other nodes that would otherwise not be able to reach one another. In our calculation of this metric, all edge weights are considered equal. The size of the node denotes degree centrality: the more connections a node has with other nodes, the bigger it appears. The network metrics can be found in supplementary material (S1) 
like SDGs 3 (good health and well-being), 4 (quality education) and 5 (gender equality).

Furthermore, it is challenging to avoid the duplication of efforts or conflicting activities between both post-2015 agendas. Considering the multitude of institutions involved in the climate change and sustainable development regime complexes, as well as the high number of climate initiatives registered on the NAZCA platform, it is important to find mechanisms through which actors can coordinate their actions to capitalize on each other's work. This is particularly important in view of the limited human and financial resources, and a diverse pool of knowledge and capabilities that often remains untapped due to a lack of cooperation and integration (UNFCCC 2017). The growing awareness for the need to connect both agendas has led to concrete efforts to promote interlinkages between them. For example, the United Nations Department of Economic and Social Affairs (UN DESA) and the UNFCCC Secretariat convened a multi-stakeholder conference entitled "Strengthening Synergies between the Paris Agreement and the 2030 Agenda for Sustainable Development" in 2019, inviting participants to discuss joint implementation efforts (United Nations 2019). Additionally, one can filter the climate actions registered at the NAZCA platform according to different topics, such as transport or water. Likewise, at the CIP database, actors can now indicate whether their efforts relate to the SDGs. ${ }^{17}$ These examples illustrate that global governance institutions like the UNFCCC increasingly try to map the TCI landscape, cluster them according to various themes or SDGs, and organize targeted events to create awareness about the interlinkages between climate actions and sustainable development.

Second, we gained additional insights when comparing our results to existing findings about the interlinkages between national state-led climate actions and the SDGs. This is particularly interesting, as non-state actions are increasingly acknowledged as to fill gaps in the existing climate governance regime (Andonova et al. 2017; Hsu et al. 2016; Tosun and Schoenefeld, 2017) not solely in scientific debates, but also by the UN and UNFCCC, as demonstrated by the fact that they provide platforms and register initiatives under the "Partnerships for SDGs" and "NAZCA" databases (Chan et al. 2019). By implementing projects across sectors and borders, non-state actors can initiate climate actions in areas that are beyond the reach of national governments. As the UNFCCC Secretariat highlights, "in many cases, the private sector, NGOs and civil society have

\footnotetext{
$\overline{17}$ However, this data was not available when we retrieved our data from the CIP platform. Additionally, this self-reported data is arguably less reliable than our dataset because it may be based on a simple "box-ticking" approach that carries the risk of overrepresenting some SDGs.
}

a part to play in pursuing the [two] agendas, particularly in areas where the government actors may lack the will or capacity" (UNFCCC 2017, pp. 17-18). Given the rather "soft" governance functions assumed by non-state actors described earlier, the question arises whether TCIs simply reproduce the pattern of alignment between both agendas at the state level, or whether they actually complement these actions. To answer this question, we compared our findings to the results of a study that analyzed NDC-SDG connections (Brandi et al. 2017b). That study used a very similar methodology, as Brandi et al. (2017a) also employed content analysis to identify the thematic linkages between state-led climate actions and the SDGs. The main difference between that study and our research here is the number of climate actions that were analyzed. Brandi et al. (2017b) identified 7,080 climate actions from 161 NDCs (for details on methodology, see Brandi et al. 2017a), while we counted 258 thematic linkages between 72 climate actions and the SDGs. However, the results of both studies can arguably be compared, particularly when one focuses on the relative distribution of SDGs addressed across all climate actions. Figure 8 shows that transnational climate actions have the most interlinkages with SDG 13 (climate action). In contrast, Brandi et al. (2017b) found that most climate activities set out in the NDCs connect with SDG 7 (affordable and clean energy). Both studies show that SDG 5 (gender equality) and SDG 16 (peace, justice and strong institutions) are very weakly aligned with climate actions, and SDGs $4,8,11$ and 14 demonstrate a relatively similar degree of alignment compared to other SDGs.

A striking difference between both studies concerns the interlinkages between climate actions and SDG 12 regarding responsible consumption and production. While national climate actions are only weakly connected to SDG 12 , this goal is most often addressed by transnational climate actions. Thus, TCIs appear to fill a governance gap in mobilizing consumers and producers to take action. At the target level, state actors mainly address target 12.4 (environmentally sound management of chemicals and all wastes) and 12.5 (reducing waste generation) (Brandi et al. 2017b), while TCIs take a complementary role by focusing on target 12.6 (sustainable business practices). We further found that, relatively speaking, a greater number of TCIs address SDG 9 (industry, innovation and infrastructure) compared to actions at the national level. While both transnational and national climate actions most often relate to target 9.4 (upgrade infrastructure and retrofit industries) and target 9.1 (resilient infrastructure), TCIs complement actions at the national level with regard to target 9.5 (research and innovation). SDG 10 (reduced inequalities) constitutes a third issue area for which we find greater interlinkages with climate actions at the transnational level. While NDC actions prioritize the social, economic and political inclusion of all 


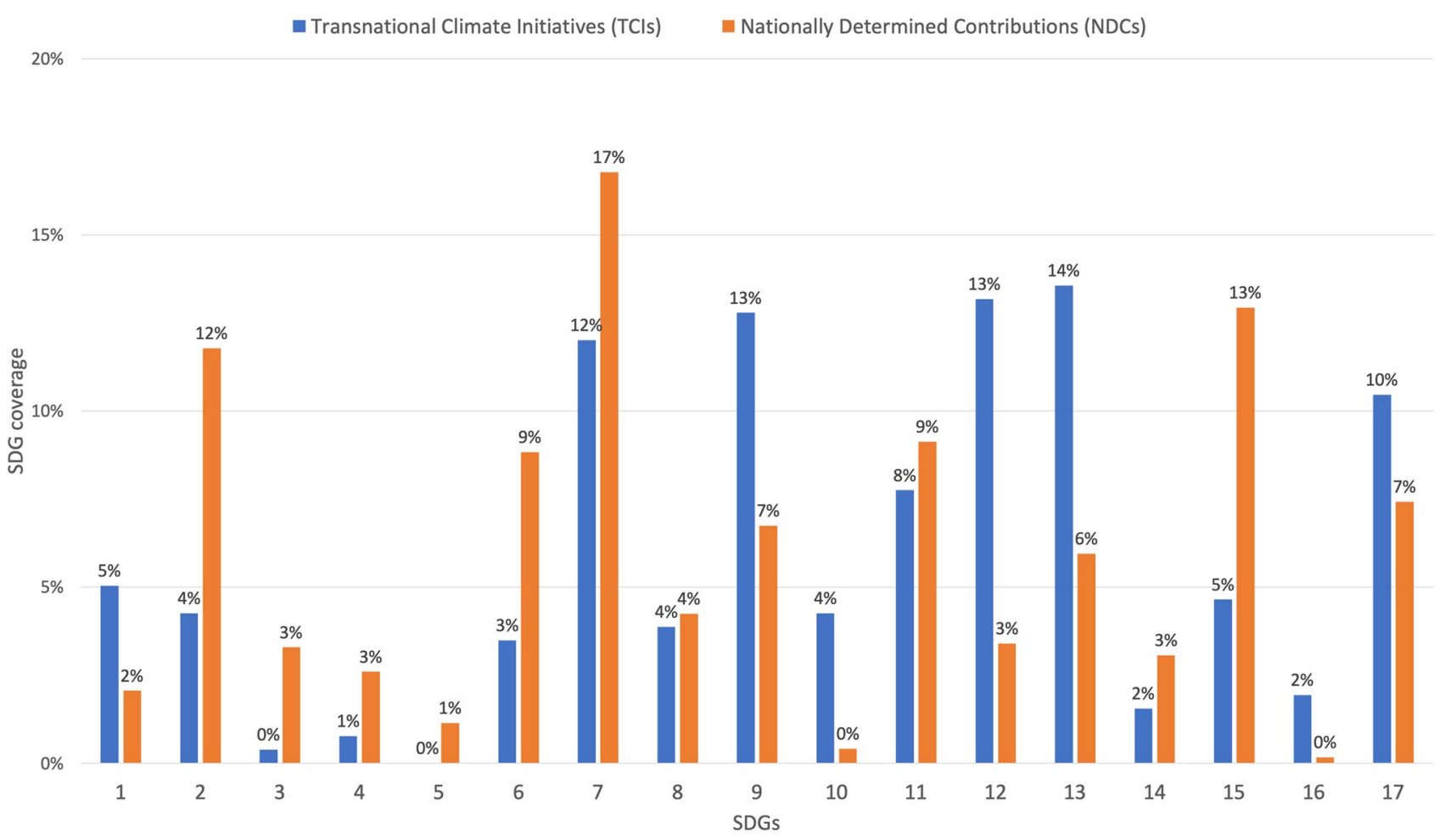

Fig. 8 Interlinkages between transnational climate actions and the SDGs (own data) compared to interlinkages between national climate actions and the SDGs (based on data from Brandi et al. 2017b). The absolute numbers can be found in supplementary material S2

(target 10.2) and social protection policies (target 10.4), TCIs add to these efforts by encouraging financial flows and foreign direct investment to the world's poorest regions (target 10.b) and by contributing to improved regulation and monitoring of financial markets (target 10.5).

Furthermore, TCIs show a greater focus on resilience and adaptation measures than state-led climate actions. While the climate actions formulated under the NDCs show a relatively weak connection to SDG target 13.1 (climate change adaptation and resilience) and target 1.5 (resilience of the poor) (Brandi et al. 2017b), TCIs align well with these two targets. In contrast, national climate actions connect better with SDG 15, particularly target 15.2 (sustainable forest management and halting deforestation). This is surprising because transnational initiatives have proliferated in the forestry sector in recent decades (Overdevest and Zeitlin, 2014). Potential reasons for this bolstered role of state actors in addressing SDG 15 could be the principle of national sovereignty over forest exploitation (Overdevest and Zeitlin, 2014) and the fact that private governance initiatives like certification schemes for forestry products have not been registered at the NAZCA platform. The last major difference is that NDCs address SDG 2 (zero hunger) more often than transnational initiatives. Nonetheless, at the target level, target 2.4 (sustainable agricultural production systems) is the most frequently addressed target in both international and transnational climate actions. In sum, our findings indicate that transnational actors complement state-led interventions in climate and sustainability governance. Our study supports the argument by Andonova et al. (2017, p. 253), who explain that "we should understand national policies and transnational governance as complements, rather than competitors"; and generally, further strengthens the yet growing optimism about the role of transnational and non-state actions in global climate and sustainability governance (Chan et al. 2019).

The third and last point of our discussion is a reflection on the strengths and weaknesses of our methodological approach, particularly the use of network analysis techniques. The network perspective provides easily accessible information about (1) which SDGs function as connectors of other pairs of SDGs, (2) which SDGs and initiatives cluster in sub-groups and (3) which SDGs show the greatest potential for joint implementation due to thematic overlaps. In addition, viewing the SDGs as a network can help to avoid retreating into silo particularism, which involves failing to account for the crosscutting nature of many SDGs. Aligning TCIs and the SDGs requires identifying the actual or potential co-benefits between climate actions and particular SDGs, while at the same time acknowledging the network structure of the SDGs. Not only does the network approach 
help to recognize synergistic SDGs, but it can also help identify which climate initiatives could benefit from collaboration and exchange. Therefore, network analysis is a valuable analytical tool for researchers and practitioners alike. For example, an egocentric network on specific targets can reveal which initiatives will likely benefit from cooperation with one another, e.g., through learning about best practices and pitfalls of their peers (see Appendix A3 for example). Finally, making use of interactive online platforms to present network data provides a valuable opportunity to communicate scientific research results with practitioners, and to encourage scholars and policy-makers to explore the complex system of interlinkages between climate actions and the broader Agenda 2030. ${ }^{18}$

Our analysis has several limitations. First, we only analyzed cooperative climate initiatives, which represent just a small fraction of all climate actions registered on the NAZCA platform. In total, several thousand climate actions by different countries, cities, regions, companies, investors and organizations are listed on the NAZCA platform. Since this study focuses on transnational governance arrangements, we limited our analysis to cooperative initiatives involving a diverse set of non-state actors. Further, we assumed that the initiatives would show greater heterogeneity with respect to SDG linkages than initiatives of single actor groups, such as cities, which might be centered around particular SDGs like SDG 11 (sustainable cities and communities). Future studies could explore and compare the SDG networks that underlie climate actions by different groups of actors or conduct a social network analysis of the different types of actors involved in such collaborative arrangements. Second, since the NAZCA platform and the Climate Initiatives Platform rely on self-reported information, the level of detail and accuracy of data may vary between different initiatives. The information on some initiatives may be updated more regularly, accurately and extensively than others. Third, our methodological approach cannot capture trade-offs between the SDGs. It focuses on how initiatives thematically overlap and identifies potential synergies, but it does not determine where overlaps are missing or where they result in disruptive trade-offs. Previous research has shown that, while there are far more synergies between climate action and the SDGs, there are also trade-offs that nevertheless have the potential to block climate action or delivery on the SDGs (Nerini et al. 2019). For example, if climate policies are not properly designed, they can exacerbate inequality and poverty (SDG 1.1 and 1.2), and hamper a just transition to sustainable agriculture (SDG 2.3 and 2.4) and industrialization (SDG 9.2) (Nerini et al. 2019). While it

\footnotetext{
18 Interested readers can explore our network at: https://kumu.io/-/ 202345\#map-UsyuvvlU
}

goes beyond the scope of our analysis to assess such tradeoffs, it is important to take into account that these are likely to occur between climate action TCIs and the SDG. Network analysis techniques can be used to study constraining or counteractive interactions between SDGs, but doing so requires expert judgments about the scoring of interactions (Weitz et al. 2018). Lastly, our network approach does not allow one to make any inferences about the type of a positive interaction between SDGs, which have been conceptualized by Nilsson et al. (2016) as enabling, reinforcing or indivisible relations.

\section{Conclusion}

Transnational climate actions can promote wider social, economic and environmental development goals. Out of the 72 multi-stakeholder climate initiatives that we analyzed in this study, 71 initiatives showed thematic interlinkages with the SDGs in their proposed actions. The strongest links exist between TCIs and SDG 13 (climate action), followed by SDGs 12 (responsible consumption and production), 9 (industry, innovation and infrastructure), 7 (affordable and clean energy), and 17 (partnerships for the goals). While TCIs barely address SDGs 3 (good health and well-being) and 4 (quality education), TCIs do not cover SDG 5 (gender equality) at all. Thus, climate actions around sustainable production and consumption, energy, and industry and infrastructure appear to be key for combating climate change while simultaneously fostering sustainable development.

Applying network analysis techniques enabled us to go beyond simply quantitatively describing which SDGs are covered by transnational climate actions and to investigate the interactions between individual SDGs. Up until now, social science research has usually employed network analysis for studying social or citation networks. We demonstrate that network analysis techniques can yield fruitful insights when applied to new contexts, such as interlinkages between the SDGs created through transnational climate actions. Our network visualizations highlight the synergistic relations between several SDGs, particularly SDG 9 (industry, innovation and infrastructure), which is often addressed in combination with SDGs 7 (affordable and clean energy), 11 (cities), 12 (responsible consumption and production), 17 (partnerships for the goals) and 13 (climate action). The network reveals that SDG 9 is highly synergistic with many other frequently addressed SDGs. This is not evident when only considering the descriptive statistical analysis regarding SDG coverage. The network perspective helps to break down complex interconnections and makes information easily accessible, comprehensible and useful for both scholars and policy-makers. It demonstrates which initiatives could benefit from sharing information and best practices with one 
another due to their close location in the network, which implies some thematic overlaps of their actions.

The challenges for aligning climate actions and the SDGs stem from the need to connect actors, institutions, themes and sectors. Considering the different capacities and responsibilities of state and non-state actors, coordinated actions must take place across geographic and knowledge borders. Even though the wording of some SDG targets suggests that actions in certain issue areas fall into the sole responsibility of state actors, one must acknowledge that non-state actors can play an important complementary role in achieving the state-led global Paris Agreement and Agenda 2030. TCIs generally assume rather soft governance functions within the climate and sustainability regime complex, such as, inter alia, knowledge sharing or mobilization of public engagement. Political decision-makers should thus be encouraged to design open and inclusive policy-making, implementation and monitoring processes to harness the complementary potential between state and non-state actor contributions. Mutual learning, as well as sharing of resources and best practices between different stakeholder groups could then contribute to a more effective and efficient implementation of the Paris Agreement and the SDGs. Our findings present a first step in raising awareness about how TCIs can contribute to the achievement of the SDGs. In particular, the presence of common themes in both agendas provides a major opportunity to align actions that address climate change and further sustainable development. By pursuing actions that address common themes, such as resilience, energy or infrastructure, policy-makers and practitioners, can contribute to a joint implementation of both agendas.

There are several questions that remain unaddressed. A detailed analysis of the actors involved in TCIs could be further expanded to scrutinize power relations, interest politics and geographic (im)balances in the context of global environmental and sustainability governance. Another question worth investigating is whether transnational initiatives effectively meet their commitments and are held accountable for achieving their objectives. The NAZCA platform mobilizes a broad set of actors, covering issues from food waste to urban transportation, thus making it difficult to evaluate their performance against a common yardstick. Future research could examine whether TCIs actually provide the co-benefits they set out to achieve. Equally relevant is the counter question: when implementing transnational climate actions, what trade-offs with regards to other sustainability goals are made? While this article focuses on synergies, future research should also study the disruptive connections between climate actions and the SDGs. Extending the analysis by clustering TCIs according to specific themes, such as energy or resilience, might further yield interesting findings. A particularly relevant task for future research is to demonstrate how the interlinkages between weakly or not covered SDGs, such as SDG 5 (gender equality), can be strengthened. Lastly, many TCIs are not formally integrated into NAZCA. Follow-up research could involve a broader sample size and include additional initiatives that are not covered by the NAZCA registry.

This article represents an effort to consider climate actions within and across sectors of sustainable development and as a complex series of interlinkages. It encourages discussions, critical reflections and engagement with the two post-2015 agendas at the transnational level. Our findings contribute towards identifying entry points to jointly govern, implement and achieve both agendas to ensure a carbon-neutral, climate-resilient and sustainable global development path.

\section{Appendix A1: Cooperative NAZCA initiatives}

\begin{tabular}{ll}
\hline Code used in network & Full name \\
\hline I_1 & 4/1000 Initiative-Soils for Food \\
& Security and Climate \\
I_2 & Adaptation for Smallholder Agri- \\
culture Programme (ASAP) & Adaptation of West African \\
I_3 & Coastal Areas \\
& Africa Renewable Energy Initia- \\
I_4 & tive \\
I_5 & Airport Carbon Accreditation \\
& (ACI) \\
I_6 & Blue Growth Initiative \\
I_7 & Bonn Challenge-Landscape \\
& Restoration \\
I_8 & Breakthrough Energy Coalition \\
I_9 & Business Alliance for Water and \\
& Climate \\
I_10 & Business Leadership Criteria on \\
& Carbon Pricing \\
I_11 & C40 Clean Bus Declaration \\
I_12 & Carbon Neutral Cities Alliance \\
I_13 & Caring for Climate \\
I_14 & CCAC: Phasing Down Climate \\
I_15 & Potent HFCs / HFCs Initiative \\
I_16 & CCAC: Oil and Gas Methane \\
I_17 & Partnership \\
I_18 & CEM: Global Lighting Challenge \\
I_19 & Cities and regions 5-year vision \\
I_20 & Cities Climate Finance Leadership \\
& Clean Energy Corridors in Africa \\
\hline & \\
&
\end{tabular}




\begin{tabular}{|c|c|}
\hline Code used in network & Full name \\
\hline I_21 & $\begin{array}{l}\text { Climate Risk and Early Warning } \\
\text { Systems Initiative }\end{array}$ \\
\hline I_22 & $\begin{array}{l}\text { Collaborative Climate Action } \\
\text { Across the Air Transport World }\end{array}$ \\
\hline I_23 & Compact of Mayors \\
\hline I_24 & $\begin{array}{l}\text { Corporate Engagement in Climate } \\
\text { Policy }\end{array}$ \\
\hline I_25 & $\begin{array}{l}\text { Covenant of Mayors for Climate } \\
\text { \& Energy }\end{array}$ \\
\hline I_26 & Divest-Invest Global Movement \\
\hline I_27 & En.lighten Initiative \\
\hline I_28 & $\begin{array}{l}\text { Food Security Climate Resilience } \\
\text { Facility }\end{array}$ \\
\hline I_29 & $\begin{array}{l}\text { Global Alliance for Buildings and } \\
\text { Construction }\end{array}$ \\
\hline I_30 & $\begin{array}{l}\text { Global Alliance for Clean Cook- } \\
\text { stoves }\end{array}$ \\
\hline I_31 & $\begin{array}{l}\text { Global Fuel Economy Initiative } \\
\text { (GFEI) }\end{array}$ \\
\hline I_32 & Global Geothermal Alliance \\
\hline I_33 & Global Resilience Partnership \\
\hline I_34 & $\begin{array}{c}\text { Great Green Wall for Sahara and } \\
\text { the Sahel Initiative (GGWSSI) }\end{array}$ \\
\hline I_35 & $\begin{array}{l}\text { InsuResilience Climate Risk } \\
\text { Insurance Initiative }\end{array}$ \\
\hline I_36 & International Solar Alliance \\
\hline I_37 & $\begin{array}{l}\text { International Zero-Emission Vehi- } \\
\text { cle Alliance (ZEV Alliance) }\end{array}$ \\
\hline I_38 & $\begin{array}{l}\text { LCTPi Cement Sustainability } \\
\text { Initiative }\end{array}$ \\
\hline I_39 & LCTPi Renewables \\
\hline I_40 & Life Beef Carbon Initiative \\
\hline I_41 & $\begin{array}{l}\text { Low-Carbon Sustainable Rail } \\
\text { Transport Challenge }\end{array}$ \\
\hline I_42 & $\begin{array}{l}\text { Maritime Regions in Action } \\
\text { against Climate Change }\end{array}$ \\
\hline I_43 & $\begin{array}{l}\text { Megacities Alliance for Water and } \\
\text { Climate }\end{array}$ \\
\hline I_44 & Mission Innovation \\
\hline I_45 & MobiliseYourCity Partnership \\
\hline I_46 & Montreal Carbon Pledge \\
\hline I_47 & $\begin{array}{l}\text { Paris Declaration on Electromo- } \\
\text { bility on Climate Change }\end{array}$ \\
\hline I_48 & $\begin{array}{l}\text { Paris Pact on Water and Adapta- } \\
\text { tion }\end{array}$ \\
\hline I_49 & $\begin{array}{l}\text { Portfolio Decarbonization Coali- } \\
\text { tion }\end{array}$ \\
\hline
\end{tabular}

\begin{tabular}{|c|c|}
\hline Code used in network & Full name \\
\hline I_50 & $\begin{array}{l}\text { Promotion of Smart Agriculture } \\
\text { Towards Climate Change }\end{array}$ \\
\hline I_51 & $\begin{array}{l}\text { Protection of } 400 \text { million Hectares } \\
\text { of Forests }\end{array}$ \\
\hline I_52 & $\begin{array}{l}\text { Public Transport Declaration on } \\
\text { Climate Leadership (UITP) }\end{array}$ \\
\hline I_53 & R4 Rural Resilience Initiative \\
\hline I_54 & RE100 \\
\hline I_55 & Refrigerants, Naturally! \\
\hline I_56 & $\begin{array}{l}\text { Remove commodity-driven defor- } \\
\text { estation }\end{array}$ \\
\hline I_57 & Save Food initiative \\
\hline I_58 & Science Based Targets initiative \\
\hline I_59 & $\begin{array}{l}\text { SE4All: Building Efficiency } \\
\text { Accelerator }\end{array}$ \\
\hline I_60 & $\begin{array}{l}\text { SE4All: Global Energy Efficiency } \\
\text { Accelerator Platform (Main) }\end{array}$ \\
\hline I_61 & $\begin{array}{l}\text { SE4All: District Energy Accelera- } \\
\text { tor }\end{array}$ \\
\hline I_62 & SIDS Lighthouses Initiative \\
\hline I_63 & Smart Risk Investing (SRI) \\
\hline I_64 & $\begin{array}{l}\text { States and Regions Annual Dis- } \\
\text { closure }\end{array}$ \\
\hline I_65 & Taxi4SmartCities \\
\hline I_66 & The 1-in-100 Initiative \\
\hline I_67 & $\begin{array}{l}\text { The New York Declaration on } \\
\text { Forests }\end{array}$ \\
\hline I_68 & Under $2 \mathrm{MOU}$ \\
\hline I_69 & United for Efficiency \\
\hline I_70 & Urban Electric Mobility Initiative \\
\hline I_71 & WWF Climate Savers \\
\hline I_72 & $\begin{array}{l}\text { Zero Deforestation Commitments } \\
\text { from Commodity Producers and } \\
\text { Traders }\end{array}$ \\
\hline Excluded & Global Green Freight Action Plan ${ }^{b}$ \\
\hline Excluded & $\begin{array}{l}\text { Industry Energy Efficiency } \\
\text { Accelerator }^{\mathrm{a}}\end{array}$ \\
\hline Excluded & Lima Challenge $^{\mathrm{a}}$ \\
\hline Excluded & Municipal Solid Waste Initiative ${ }^{a}$ \\
\hline Excluded & $\begin{array}{l}\text { Statement by Financial Institutions } \\
\text { on Energy Efficiency Finance }^{\mathrm{a}}\end{array}$ \\
\hline
\end{tabular}

Source: NAZCA (2018a; b). Data retrieved in April 2018

${ }^{a}$ Data is unavailable on Climate Initiatives Platform (2018a, 2019a; $b, b, c)$

${ }^{\mathrm{b}}$ Data is incomplete on Climate Initiatives Platform (2018a, 2019a; b, b, c) 


\section{Appendix A2: Illustrative examples of text passages that are coded for their interlinkages with the SDGs}

\begin{tabular}{|c|c|}
\hline Example & Target \\
\hline $\begin{array}{l}\text { "Scale up the Africa's renewable energy } \\
\text { potential to achieve at least } 10 \mathrm{GW} \text { of } \\
\text { new and additional renewable energy } \\
\text { generation capacity by } 2020 \text { and at } \\
\text { least } 300 \mathrm{GW} \text { by } 2030[\ldots] \text { The overall } \\
\text { goal of AREI is to produce } 300 \mathrm{GW} \\
\text { of electricity for Africa by } 2030 \text { from } \\
\text { clean, affordable and appropriate forms } \\
\text { of energy" }\end{array}$ & $\begin{array}{l}\text { Goal 7. Ensure access to affordable, reliable, sustainable and modern energy for all } \\
\text { Target 7.1: By 2030, ensure universal access to affordable, reliable and modern energy services } \\
\text { Target 7.2: By 2030, increase substantially the share of renewable energy in the global energy mix }\end{array}$ \\
\hline $\begin{array}{l}\text { "Restore } 150 \text { million hectares of the } \\
\text { world's deforested and degraded lands } \\
\text { by } 2020 "\end{array}$ & $\begin{array}{l}\text { Goal 15. Protect, restore and promote sustainable use of terrestrial ecosystems, sustainably manage } \\
\text { forests, combat desertification, and halt and reverse land degradation and halt biodiversity loss } \\
\text { Target 15.1: By 2020, ensure the conservation, restoration and sustainable use of terrestrial and inland } \\
\text { freshwater ecosystems and their services, in particular forests, wetlands, mountains and drylands, in } \\
\text { line with obligations under international agreements } \\
\text { Target 15.2: By 2020, promote the implementation of sustainable management of all types of forests, } \\
\text { halt deforestation, restore degraded forests and substantially increase afforestation and reforestation } \\
\text { globally } \\
\text { Target 15.3: By 2030, combat desertification, restore degraded land and soil, including land affected } \\
\text { by desertification, drought and floods, and strive to achieve a land degradation-neutral world }\end{array}$ \\
\hline $\begin{array}{l}\text { "A company joining the CCAC Oil \& } \\
\text { Gas Methane Partnership voluntarily } \\
\text { commits itself to survey for nine core } \\
\text { sources that account for the bulk of } \\
\text { methane emissions in typical upstream } \\
\text { operation [...]" }\end{array}$ & $\begin{array}{l}\text { Goal 12. Ensure sustainable consumption and production patterns } \\
\text { Target 12.6: Encourage companies, especially large and transnational companies, to adopt sustainable } \\
\text { practices and to integrate sustainability information into their reporting cycle }\end{array}$ \\
\hline
\end{tabular}

\section{Appendix A3: Egocentric network of SDG target 7.2 regarding increasing the share of renewable energy in the global energy mix}

The TCIs involved in the network will likely benefit from learning about best practices and pitfalls of their peers because they all work on a similar topic.

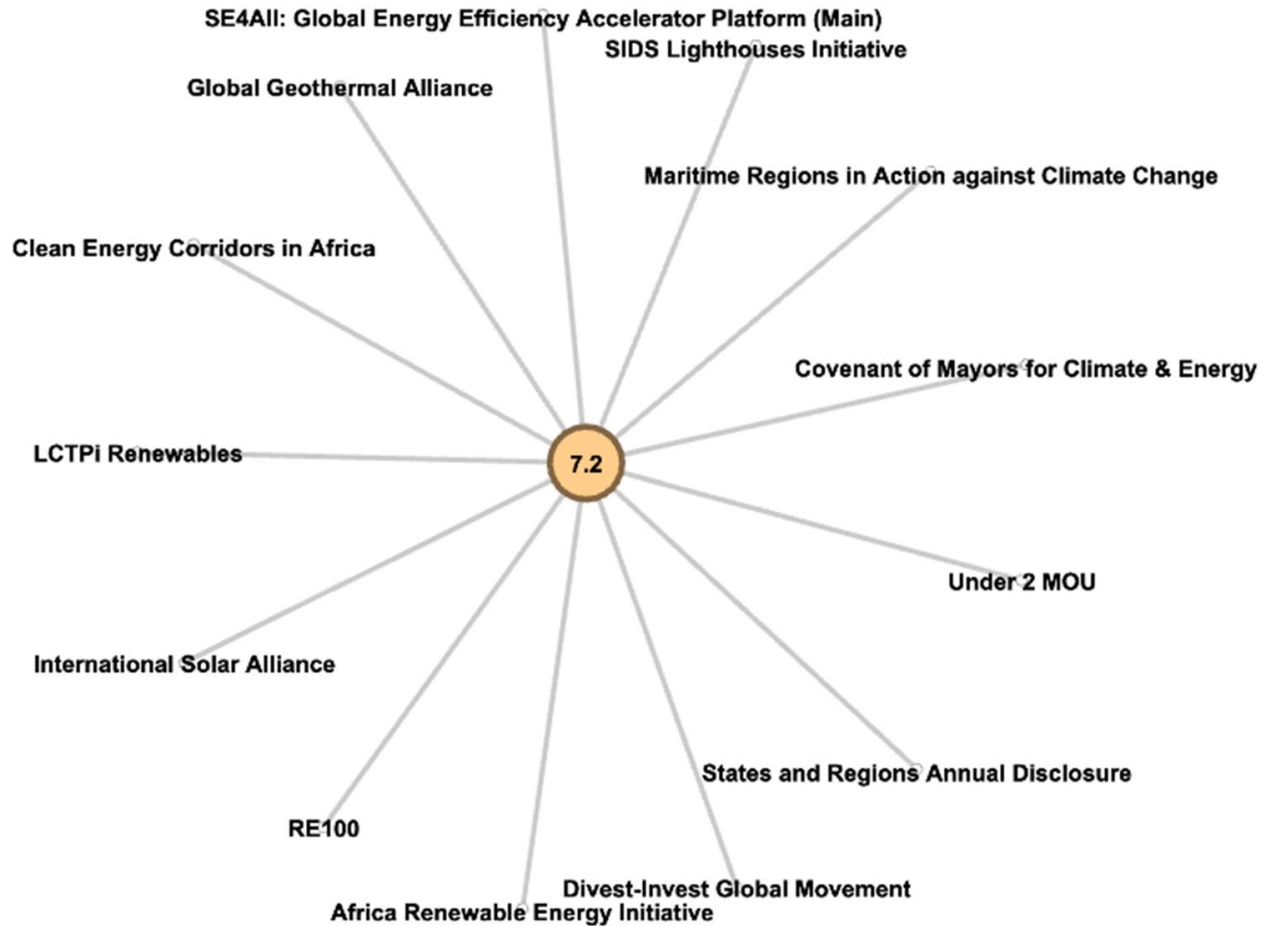


Supplementary Information The online version contains supplementary material available at https://doi.org/10.1007/s11625-021-01007-9.

Acknowledgements We would like to thank Philipp Pattberg for his valuable comments on the outline of this study, and Christoph Martin for kindly answering our questions about network analysis techniques. We further thank participants of the 2019 Earth System Governance Conference and the 2020 SDG Research Symposium GlobalGoals2020, in particular the panel chairs, discussants and co-panelists, for their helpful suggestions for improvements. The first author acknowledges support from the European Union's Horizon 2020 research and innovation programme under the Marie Skłodowska-Curie grant agreement No 765408 (COUPLED).

Funding Open Access funding enabled and organized by Projekt DEAL.

Data availability We invite interested readers to explore our network at: https://kumu.io/-/202345\#map-UsyuvvlU

\section{Declarations}

Conflict of interest The authors declare that they have no competing interests.

Open Access This article is licensed under a Creative Commons Attribution 4.0 International License, which permits use, sharing, adaptation, distribution and reproduction in any medium or format, as long as you give appropriate credit to the original author(s) and the source, provide a link to the Creative Commons licence, and indicate if changes were made. The images or other third party material in this article are included in the article's Creative Commons licence, unless indicated otherwise in a credit line to the material. If material is not included in the article's Creative Commons licence and your intended use is not permitted by statutory regulation or exceeds the permitted use, you will need to obtain permission directly from the copyright holder. To view a copy of this licence, visit http://creativecommons.org/licenses/by/4.0/.

\section{References}

Abbott KW (2012) The transnational regime complex for climate change. Eviron Plann C 30(4):571-590. https://doi.org/10.1068/ c11127

Adshead D, Thacker S, Fuldauer LI, Hall JW (2019) Delivering on the Sustainable Development Goals through long-term infrastructure planning. Glob Environ Chang 59:101975. https://doi.org/10. 1016/j.gloenvcha.2019.101975

Allen MR, Coninck H de, Dube OP, Hoegh-Guldberg O, Jacob D, Jiang K, Zhou G (2019) Technical Summary. In: Masson-Delmotte V, Zhai P, Pörtner H-O, Roberts D, Skea J, Shukla PR, Waterfield T (eds), Global Warming of $1.5^{\circ} \mathrm{C}$. An IPCC Special Report on the impacts of global warming of $1.5^{\circ} \mathrm{C}$ above pre-industrial levels and related global greenhouse gas emission pathways, in the context of trengthening the global response to the threat of climate change. Retrieved from https://www.ipcc.ch/site/assets/uploads/ sites/2/2019/05/SR15_TS_High_Res.pdf. Accessed 5 July 2021

Andonova LB, Hale TN, Roger CB (2017) National policy and transnational governance of climate change: Substitutes or complements? Int Stud Quart 61(2):253-268. https://doi.org/10.1093/isq/sqx014

Antwi-Agyei P, Dougill AJ, Agyekum TP, Stringer LC (2018) Alignment between nationally determined contributions and the Sustainable Development Goals for West Africa. Clim Policy
18(10):1296-1312. https://doi.org/10.1080/14693062.2018.14311 99

Bäckstrand K (2006) Multi-stakeholder partnerships for sustainable development: rethinking legitimacy, accountability and effectiveness. Eur Environ 16(5):290-306. https://doi.org/10.1002/eet.425

Bäckstrand K, Kuyper JW, Linnér BO, Lövbrand E (2017) Non-state actors in global climate governance: from Copenhagen to Paris and beyond. Environ Polit 26(4):561-579. https://doi.org/10.1080/ 09644016.2017.1327485

Beg N, Morlot JC, Davidson O, Afrane-Okesse Y, Tyani L, Denton F, Rahman AA (2002) Linkages between climate change and sustainable development. Clim Policy 2(2-3):129-144. https://doi.org/ 10.3763/cpol.2002.0216

Bennich T, Weitz N, Carlsen H (2020) Deciphering the scientific literature on SDG interactions: A review and reading guide. Sci Total Environ 728:138405. https://doi.org/10.1016/j.scitotenv. 2020.138405

Biermann F, Pattberg P (eds) (2012) Global environmental governance reconsidered. The MIT Press, Cambridge

Biermann F, Pattberg P, van Asselt H, Zelli F (2009) The fragmentation of global governance architectures: a framework for analysis. Glob Environ Polit 9(4):14-40. https://doi.org/10.1162/glep. 2009.9.4.14

Börzel TA, Risse T (2010) Governance without a state: can it work? Regul Gov 4(2):113-134. https://doi.org/10.1111/j.1748-5991. 2010.01076.x

Brandi C, Dzebo A, Janetschek H, Lambert C, Savvidou G (2017a) How did we do this? The NDC-SDG Connections tool. https:// klimalog.die-gdi.de/ndc-sdg/assets/downloads/HowdidwedothisNDCSDGConnections.pdf. Retrieved 20 June 2018

Brandi C, Dzebo A, Janetschek H, Lambert C, Savvidou G (2017b) NDC-SDG connections. German Development Institute/ Deutsches Institut für Entwicklungspolitik (DIE), Stockholm Environment Institut (SEI). https://doi.org/10.23661/ndc-sdg_ 2017_1.0

Breuer A, Janetschek H, Malerba D (2019) Translating Sustainable Development Goal (SDG) interdependencies into policy advice. Sustainability 11(7):2092. https://doi.org/10.3390/su11072092

Bulkeley H, Andonova L, Bäckstrand K, Betsill M, Compagnon D, Duffy R, VanDeveer S (2012) Governing climate change transnationally: assessing the evidence from a database of sixty initiatives. Eviron Plann C 30(4):591-612. https://doi.org/10.1068/ c11126

Chan S, Amling W (2019) Does orchestration in the Global Climate Action Agenda effectively prioritize and mobilize transnational climate adaptation action? Int Environ Agreem 19:429-446. https://doi.org/10.1007/s10784-019-09444-9

Chan S, Brandi C, Bauer S (2016) Aligning transnational climate action with international climate governance: the road from Paris. Rev Eur Comp Int Environ Law 25(2):238-247. https://doi.org/10. 1111/reel.12168

Chan S, Boran I, van Asselt H, Iacobuta G, Niles N, Rietig K, Wambugu $\mathrm{G}$ (2019) Promises and risks of nonstate action in climate and sustainability governance. Wiley Interdiscipl Rev 10(3):1-8. https://doi.org/10.1002/wcc.572

Climate Initiatives Platform (2018a) Climate initiative platform. http:// climateinitiativesplatform.org. Retrieved April 182018

Climate Initiatives Platform (2018b) Save food initiative. http:// climateinitiativesplatform.org/index.php/Save_Food_initiative Retrieved 18 Apr 2018

Climate Initiatives Platform (2019a) CEM: global lighting challenge. http://climateinitiativesplatform.org/index.php/CEM:_Global Lighting_Challenge. Retrieved 31 Mar 2021

Climate Initiatives Platform (2019b) SEforAll: building efficiency accelerator. https://climateinitiativesplatform.org/index.php? 
title=SEforAll:_Building_Efficiency_Accelerator\&redirect $=$ no. Retrieved 21 Apr 2021

Climate Initiatives Platform (2019c) United for Efficiency. http:// climateinitiativesplatform.org/index.php/United_for_Efficiency. Retrieved 29 May 2020

Dasandi N, Hudson D, Pegram T (2015) Governance and institutions. In: Waage J, Yap C (eds) Thinking beyond sectors for sustainable development. Ubiquity Press, London, pp 63-76

England MI, Stringer LC, Dougill AJ, Afionis S (2018) How do sectoral policies support climate compatible development? An empirical analysis focusing on southern Africa. Environ Sci Policy 79:915. https://doi.org/10.1016/j.envsci.2017.10.009

Eriksen S, Aldunce P, Bahinipati CS, Martins RD, Molefe JI, Nhemachena C, Ulsrud K (2011) When not every response to climate change is a good one: Identifying principles for sustainable adaptation. Clim Dev 3(1):7-20. https://doi.org/10.3763/cdev.2010. 0060

GIZ (2018) Spinning the web: the cobenefits approach to an integrated implementation of the 2030 Agenda and the Paris Agreement in Mexico. Retrieved from https://www.giz.de/en/downloads_els/ Spinning.TheWeb_Interactive-mexico.pdf. Accessed 13 March 2020

Glass L-M, Newig J (2019) Governance for achieving the Sustainable Development Goals: how important are participation, policy coherence, reflexivity, adaptation and democratic institutions? Earth Syst Gov 2:100031. https://doi.org/10.1016/j.esg.2019. 100031

Hajer M, Nilsson M, Raworth K, Bakker P, Berkhout F, de Boer Y, Kok M (2015) Beyond cockpit-ism: Four insights to enhance the transformative potential of the Sustainable Development Goals. Sustainability (Switzerland) 7(2):1651-1660. https://doi.org/10. 3390/su7021651

Hanneman RA, Riddle M (2005) Introduction to social network methods. University of California, Riverside

Hickmann T (2017) The reconfiguration of authority in global climate governance. Int Stud Rev 19(3):430-451. https://doi.org/10.1093/ isr/vix037

Hickmann T, Van Asselt H, Oberthür S, Sanderink L, Widerberg O, Zelli F (2020) Institutional interlinkages. In: Biermann F, Kim RE (eds) Architectures of earth system governance: institutional complexity and structural transformation. Cambridge University Press, Cambridge, pp 119-136

Hsu A, Cheng Y, Weinfurter A, Xu K, Yick C (2016) Track climate pledges of cities and companies. Nature 532(7599):303-306. https://doi.org/10.1038/532303a

Janetschek H, Brandi C, Dzebo A, Hackmann B (2020) The 2030 Agenda and the Paris Agreement: voluntary contributions towards thematic policy coherence. Clim Policy 20(4):430-442. https://doi.org/10.1080/14693062.2019.1677549

Jordan A, Huitema D, van Asselt H, Forster J (eds) (2018) Governing climate change: polycentricity in action? Cambridge University Press, Cambridge

Keohane RO, Victor DG (2011) The regime complex for climate change. Perspect Polit 9(1):7-23. https://doi.org/10.1017/S1537 592710004068

Kim RE (2013) The emergent network structure of the multilateral environmental agreement system. Glob Environ Chang 23:980991. https://doi.org/10.1016/j.gloenvcha.2013.07.006

Kim RE (2020) Is global governance fragmented, polycentric, or complex? The state of the art of the network approach. Int Stud Rev 22(4):903-931. https://doi.org/10.1093/isr/viz052
Kuyper JW, Linnér B-O, Schroeder H (2018) Non-state actors in hybrid global climate governance: justice, legitimacy, and effectiveness in a post-Paris era. Wiley Interdiscipl Rev 9(1):e497. https://doi.org/10.1002/wcc.497

Le Blanc D (2015) Towards integration at last? The Sustainable Development Goals as a network of targets. Sustain Dev 23(3):176-187. https://doi.org/10.1002/sd.1582

Lusseau D, Mancini F (2019) Income-based variation in Sustainable Development Goal interaction networks. Nat Sustain 2(3):242247. https://doi.org/10.1038/s41893-019-0231-4

Mayrhofer JP, Gupta J (2016) The science and politics of co-benefits in climate policy. Environ Sci Policy 57:22-30. https://doi.org/ 10.1016/j.envsci.2015.11.005

Mitchell RB, Andonova LB, Axelrod M, Balsiger J, Bernauer T, Green JF, Morin J-F (2020) What we know (and Could Know) about international environmental agreements. Glob Environ Polit 20(1):103-121. https://doi.org/10.1162/glep_a_00544

NAZCA (2018a) Montreal Carbon Pledge. https://climateaction. unfccc.int/views/cooperative-initiative-details.html?id=46. Retrieved 18 Apr 2018

NAZCA (2018b) NAZCA: Tracking Climate Action. http://clima teaction.unfccc.int/. Retrieved 18 Apr 2018

Nerini FF, Sovacool B, Hughes N, Cozzi L, Cosgrave E, Howells M, Milligan B (2019) Connecting climate action with other Sustainable Development Goals. Nat Sustain 2(8):674-680. https:// doi.org/10.1038/s41893-019-0334-y

Nilsson M, Griggs D, Visbeck M (2016) Policy: map the interactions between Sustainable Development Goals. Nat News 534:320-322

Nilsson M, Chisholm E, Griggs D, Howden-Chapman P, McCollum D, Messerli P, Stafford-Smith M (2018) Mapping interactions between the Sustainable Development Goals: lessons learned and ways forward. Sustain Sci 13(6):1489-1503. https://doi.org/10. 1007/s11625-018-0604-z

Northrop E, Biru H, Lima S, Bouyé M, Song R (2016) Examining the alignment between the intended nationally determined contributions and Sustainable Development Goals. World Resources Institute, Washington, DC

Oberthür S, Gehring T (2006) Institutional interaction in global environmental governance: synergy and conflict among International and EU policies. MIT Press, Cambridge

Opsahl T (2013) Triadic closure in two-mode networks: redefining the global and local clustering coefficients. Soc Netw 35(2):159-167. https://doi.org/10.1016/j.socnet.2011.07.001

Orsini A, Le Prestre P, Haas PM, Brosig M, Pattberg P, Widerberg O, Chandler D (2019) Forum: complex systems and international governance. Int Stud Rev. https://doi.org/10.1093/isr/viz005

Overdevest C, Zeitlin J (2014) Assembling an experimentalist regime: Transnational governance interactions in the forest sector. Regul Gov 8(1):22-48. https://doi.org/10.1111/j.1748-5991.2012. 01133.x

Pattberg P, Widerberg O (2016) Transnational multistakeholder partnerships for sustainable development: conditions for success. Ambio 45(1):42-51. https://doi.org/10.1007/s13280-015-0684-2

Pham-Truffert M, Metz F, Fischer M, Rueff H, Messerli P (2020) Interactions among Sustainable Development Goals: knowledge for identifying multipliers and virtuous cycles. Sustain Dev. https:// doi.org/10.1002/sd.2073

Pradhan P (2019) Antagonists to meeting the 2030 Agenda. Nat Sustain 2(3):171-172. https://doi.org/10.1038/s41893-019-0248-8

Pradhan P, Costa L, Rybski D, Lucht W, Kropp JP (2017) A systematic study of Sustainable Development Goal (SDG) interactions. Earth's Future 5(11):1169-1179. https://doi.org/10.1002/2017E F000632 
Putra MPIF, Pradhan P, Kropp JP (2020) A systematic analysis of water-energy-food security nexus: a South Asian case study. Sci Total Environ. https://doi.org/10.1016/j.scitotenv.2020.138451

Rockström J, Sukhdev P (2016) How food connects all the SDGs. http://www.stockholmresilience.org/research/research-news/ 2016-06-14-how-food-connects-all-the-sdgs.html. Retrieved 18 May 2018

Roelfsema M, Harmsen M, Olivier JJG, Hof AF, van Vuuren DP (2018) Integrated assessment of international climate mitigation commitments outside the UNFCCC. Glob Environ Chang 48:67-75. https://doi.org/10.1016/j.gloenvcha.2017.11.001

Rogelj J, Den Elzen M, Höhne N, Fransen T, Fekete H, Winkler H, Meinshausen M (2016) Paris Agreement climate proposals need a boost to keep warming well below $2{ }^{\circ} \mathrm{C}$. Nature 534(7609):631639. https://doi.org/10.1038/nature18307

Scharlemann JPW, Brock RC, Balfour N, Brown C, Burgess ND, Guth MK, Kapos V (2020) Towards understanding interactions between Sustainable Development Goals: the role of environment-human linkages. Sustain Sci 15(6):1573-1584. https://doi.org/10.1007/ s11625-020-00799-6

Smit B, Pilifosova O (2001) Adaptation to climate change in the context of sustainable development and equity. In: McCarthy JJ (ed) Climate change 2001: impacts, adaptation and vulnerability. IPCC working group II. Cambridge University Press, Cambridge, pp 877-912

Stafford-Smith M, Griggs D, Gaffney O, Ullah F, Reyers B, Kanie N, O'Connell D (2017) Integration: the key to implementing the Sustainable Development Goals. Sustain Sci 12(6):911-919. https:// doi.org/10.1007/s11625-016-0383-3

Tosun J, Schoenefeld JJ (2017) Collective climate action and networked climate governance. Wiley Interdiscipl Rev 8(1):e440. https://doi. org/10.1002/wcc. 440

UNFCCC (2015) Paris Agreement. Retrieved from https://unfccc.int/ files/meetings/paris_nov_2015/application/pdf/paris_agreement_ english_.pdf. Accessed 13 March 2020

UNFCCC (2017) Opportunities and options for integrating climate change adaptation with the Sustainable Development Goals and the Sendai Framework for Disaster Risk Reduction 2015-2030 [Technical paper]. Retrieved from https://unfecc.int/resource/ docs $/ 2017 / \mathrm{tp} / 03$.pdf

United Nations (2015) Transforming our world: the 2030 Agenda for Sustainable Development (A/RES/70/1). Retrieved from http:// undocs.org/A/RES/70/1

United Nations (2018) Global indicator framework for the Sustainable Development Goals and targets of the 2030 Agenda for Sustainable Development (A/RES/71/313). Retrieved from https://unsta ts.un.org/sdgs/indicators/GlobalIndicatorFrameworkafterrefine ment_Eng.pdf. Accessed 5 July 2021

United Nations (2019) Climate and SDG synergies knowledge platform. https://sustainabledevelopment.un.org/climate-sdgs-syner gies2019\#home. Retrieved 28 May 2020
United Nations Development Group (2014) Delivering the Post-2015 Development Agenda-opportunities at the national and the local level. Retrieved from https://sustainabledevelopment.un.org/conte nt/documents/1909UNDP-MDG-Delivering-Post-2015-Report2014.pdf. Accessed 13 March 2020

van Asselt H, Gupta J, Biermann F (2005) Advancing the climate agenda: exploiting material and institutional linkages to develop a menu of policy options. Rev Eur Commun Int Environ Law 14(3):255-264. https://doi.org/10.1111/j.1467-9388.2005.0440a.x

von Stechow C, McCollum D, Riahi K, Minx JC, Kriegler E, van Vuuren DP, Edenhofer O (2015) Integrating global climate change mitigation goals with other sustainability objectives: a synthesis. Annu Rev Environ Resour 40(1):363-394. https://doi.org/10. 1146/annurev-environ-021113-095626

von Stechow C, Minx JC, Riahi K, Jewell J, McCollum DL, Callaghan MW, Baiocchi G (2016) $2{ }^{\circ} \mathrm{C}$ and SDGs: united they stand, divided they fall? Environ Res Lett 11(3):034022. https://doi.org/ 10.1088/1748-9326/11/3/034022

Waage J, Yap C, Bell S, Levy C, Mace G, Pegram T, Poole N (2015) Governing Sustainable Development Goals: interactions, infrastructures, and institutions. In: Waage J, Yap C (eds) Thinking beyond sectors for Sustainable Development. Ubiquity Press, London

Weitz N, Nilsson M, Davis M (2014) A nexus approach to the post2015 agenda: formulating integrated water, energy, and food SDGs. SAIS Rev Int Aff 34(2):37-50. https://doi.org/10.1353/ sais.2014.0022

Weitz N, Strambo C, Kemp-Benedict E, Nilsson M (2017) Closing the governance gaps in the water-energy-food nexus: insights from integrative governance. Glob Environ Chang 45:165-173. https:// doi.org/10.1016/j.gloenvcha.2017.06.006

Weitz N, Carlsen H, Nilsson M, Skånberg K (2018) Towards systemic and contextual priority setting for implementing the 2030 agenda. Sustain Sci 13(2):531-548. https://doi.org/10.1007/ s11625-017-0470-0

Widerberg O (2017) Making the connections: exploring structure, performance and coordination in a fragmented global climate governance system [PhD thesis]. Retrieved from https://research. vu.nl/en/publications/making-the-connections-exploring-struc ture-performance-and-coordi-2. Accessed 22 June 2020

Young OR (2002) The institutional dimensions of environmental change: fit, interplay, and scale. MIT Press, Cambridge

Zhou X, Moinuddin M (2017) Sustainable Development Goals interlinkages and network analysis: a practical tool for sdg integration and policy coherence. Institute for Global Environmental Strategies (IGES), Hayama

Publisher's Note Springer Nature remains neutral with regard to jurisdictional claims in published maps and institutional affiliations. 